\title{
Conversion coefficients from fluence and air kerma to personal dose equivalent for monoenergetic photons using analytical fit and Monte Carlo simulation
}

\author{
Hassan Al KANTI ${ }^{1}$,a , O. EL HAJJAJI ${ }^{1}$, T. El BARDOUNI ${ }^{1}$ \\ ${ }^{I}$ Radiations and Nuclear Systems Laboratory, Abdelmalek Essaadi University, Faculty of Sciences, Tetouan, Morocco. \\ ${ }^{a}$ E-mail address: hassan.alkanti@uae.ac.ma
}

(received 4 September 2019; revised 7 December 2019; accepted 17 February 2020)

\begin{abstract}
The present study aims to calculate a new database of conversion coefficients from fluence and air Kerma to personal dose equivalent in two terms: absorbed dose and Kerma-approximations. In this work, we propose a new equation to perform an analytical fit of our Monte Carlo (MC) calculated conversion coefficients for photons for different angles. Also, we have calculated the conversion coefficients using the EGSnrc code. The conversion coefficients have been calculated for beams of monoenergetic photons from 0.015 to $10 \mathrm{MeV}$, incident on phantom ICRU for angles of incidence from $0^{\circ}$ to a $75^{\circ}$ in steps of $15^{\circ}$. Our computed values agree well when compared with those published for the ICRU 57 in Kerma-approximations with statistical uncertainties in the calculation around 2\%. We can conclude from this work that the analytical approach is successful and powerful such as Monte Carlo methods to calculate the operational quantities.
\end{abstract}

Key words: operational quantity; personal dose equivalent; conversion coefficients; fluence; air kerma; MC.

\section{Introduction}

The protection quantities are defined by the InternationalCommission on Radiological-Protection (ICRP) and operational quantities are defined by the InternationalCommission on Radiation Units and Measurements (ICRU) to protect humans from radiation. The operational quantities and the protection quantities are related to basic physical quantities, it is necessary to use the conversion coefficients [1]. So, the radiation exposure for workers and members of the general public can be evaluated from basic physical quantities values. The relationships between the basic physical quantities, the protection quantities and the operational quantities in Figure 1 [2]. The difficulty to measure organ dose directly in the field and therefore dose conversion coefficients are needed to convert measurable values such as air Kerma to organ dose [3]. So, the operational quantities have been evaluated from the air Kerma through conversion coefficients calculations from air Kerma to the personal dose equivalent and its value must provide a reasonable estimate for the protection quantities recommended by the (ICRU) [2].

The conversion coefficients for photon radiation published by (ICRP) and by (ICRU) for mono-energetic radiation fields. The protection quantity, equivalent dose in an organ or tissue, $H$, is then defined by:

$H=\sum_{R} w_{R} D_{T, R}$ where $\mathrm{D}_{T, R}$ is the main absorbed dose from the radiation of type $R$ in the specified organ or tissue $T$, and $w_{R}$ is the radiation weight factor, $w_{R}$ is assigned to be unity, for photons [4,5]. For assessment of the radiation protection quantity 'effective dose', a depth $\mathrm{d}=10 \mathrm{~mm}$ is selected.

The dose equivalent, $\mathrm{H}$, is the product of quality factor and absorbed dose at a point in tissue at that point, thus [6,7]:

$H=Q D$

Eq. 2

where $\mathrm{D}$ is the absorbed dose and $\mathrm{Q}$ is the quality factor, the quality factor $\mathrm{Q}$ equal to 1 for photons [8]. Our work can be useful to improve the protection of workers medically, industrially and in research, from potentially external radiation exposures. In ICRU 57 the conversion coefficients calculated use the Kerma-approximation method to approach CPE. The data for the quantities of $H_{\mathrm{p}}(10, \alpha)$ in absorbed dose mode for photons are lacking in that report, owing the numerical value of Kerma approaches that of the absorbed dose, to the degree that CPE exists, that radiative losses are negligible. The aim of this study is to obtain a set of conversion coefficients relating fluence and air Kerma to personal dose equivalent for a set of energy and angular dependent on two terms (absorbed dose and Kerma-approximations) for mono-energetic photons between 0.01 to $10 \mathrm{MeV}$ for angles of incidence between $0^{\circ}$ and $75^{\circ}$ in steps $15^{\circ}$, in the phantom made of ICRU tissue have been calculated with the analytical approach and MC. 


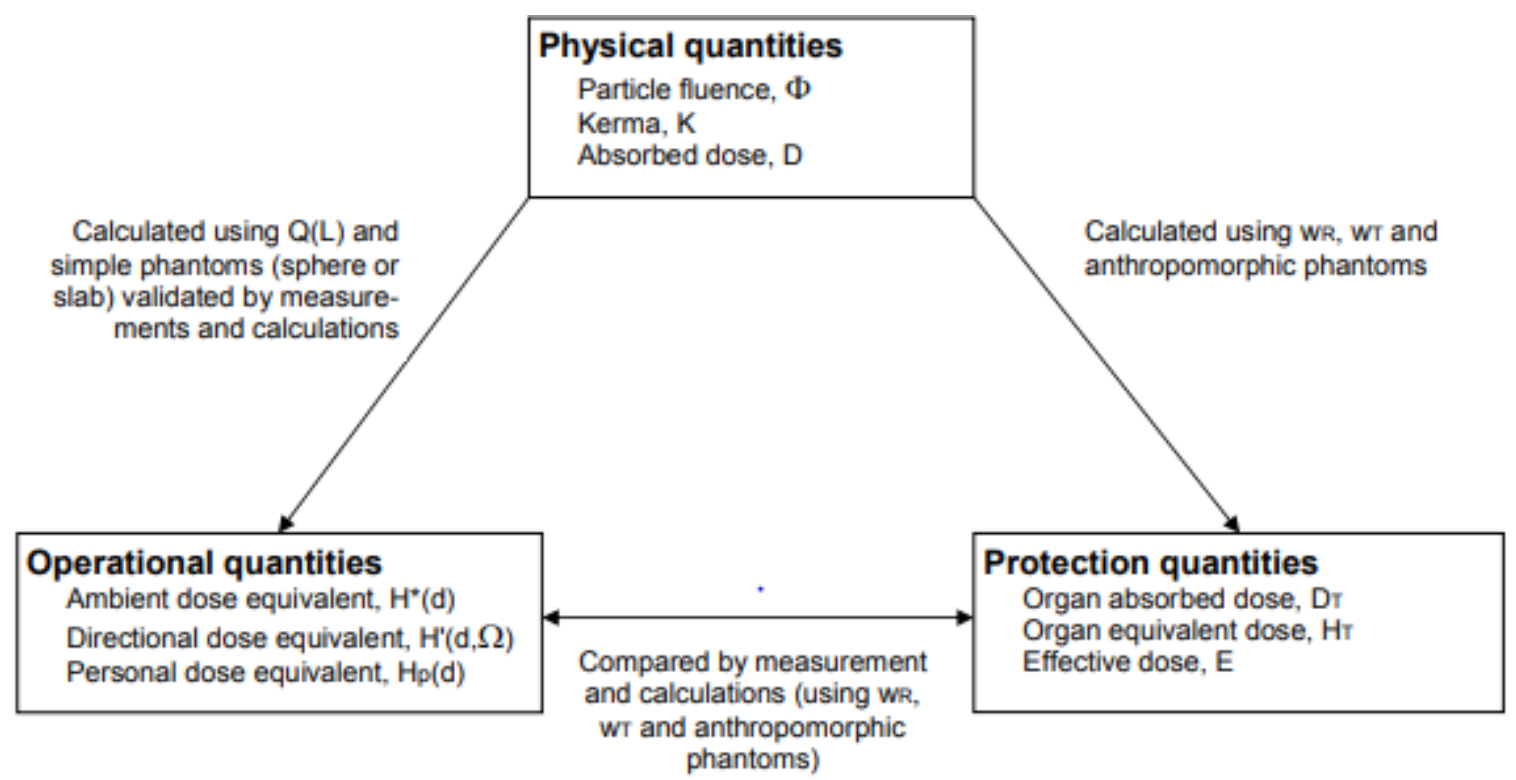

Figure 1. Relationships between the basic physical quantities, the protection quantities and the operational quantities [2].

\section{Materials and methods}

\section{Monte Carlo calculations}

The conversion-coefficients relating by physical quantities to protection quantities can estimate potential health danger for people in the case of a radiological happening. The majority of published conversion coefficients are derived from different types of Monte Carlo calculations, few are derived from measurements on anthropomorphic phantoms [9].

The Monte Carlo technique is one of the numerical methods that permit to solve complex problems by using pseudorandom numbers made by computers. The EGSnrc code is one of the general codes based on the Monte Carlo method to simulate the particle transport in matter. The calculations were carried out with the default settings, which include modeling the Compton interaction for bound electrons, the effect of any atomic relaxation events, and relativistic spin effects in the multiple scattering theories for charged particles.

For the parameters of variance reduction techniques, the default settings were used. For secondary particle production, the threshold was set to PCUT for photons and ECUT for charged particles, the photon and electron cut-off energies were set to PCUT $=10 \mathrm{keV}$ and ECUT $=521 \mathrm{keV}$, the photon crosssection packages are available in EGSnrc code for the photoelectric, pair production, triplet production, and coherent scattering cross-sections. The photon interaction cross-sections from the XCOM database were used [10].
The conversion coefficients calculation performed by the EGSnrc algorithm of PRESTA-II (called parameter reduced electron-step transport algorithm) [11], a boundary-crossing algorithm $(\mathrm{BCA}=\mathrm{EXACT}$ means crossing boundaries in a single scattering mode), maximum fractional energy loss/step $($ ESTEPE $=0.25), \quad$ maximum first elastic moment/step (XIMAX $=0.5)$ and skin-depth for boundary-crossing (MFP = 3) $[10,12]$. A total of $1 \times 10^{7}$ particles were used in order to obtain statistical uncertainty associated with the EGSnrc code in the calculation may be slim (Tables 7-17).

\section{$H_{\mathrm{p}}(\mathbf{1 0}, \alpha)$ calculations}

The EGSnrc code has been used to perform the simulation for beams of mono-energetic photons from 0.015 to $10 \mathrm{MeV}$ for angles of incidence from $0^{\circ}$ to a $75^{\circ}$ in steps of $15^{\circ}$ which incident on phantom a $30-\mathrm{cm}$-thick slab of ICRU tissues material with a density of $1 \mathrm{~g} / \mathrm{cm}^{3}$ four-element tissue and a weight composition of $76.2 \%$ oxygen $(\mathrm{O}), 11.1 \%$ carbon $(\mathrm{C})$, $10.1 \%$ hydrogen $(\mathrm{H})$, and $2.6 \%$ nitrogen $(\mathrm{N})[13,14]$. The centers of the scoring volumes are positioned on the midplane at the depth of $10 \mathrm{~mm}$, the thickness is $2 \mathrm{~mm}$ along the radius and the height is $2 \mathrm{~cm}$. Two sets of dose conversion coefficients were calculated in terms of absorbed dose and in terms of Kerma approximations, Table 1.

Table 1. The radiation, mode of conversion coefficients, quality factor Q, energies and units by EGSnrs code.

\begin{tabular}{|c|c|c|c|c|c|}
\hline Radiation & Conv & & $\mathbf{Q}$ & Energies & Units \\
\hline \multirow{4}{*}{ Photons } & \multirow{2}{*}{$\begin{array}{l}H_{\mathrm{p}}(10, \alpha) / \Phi=\mathrm{Q} \times \mathrm{D}(10, \alpha) / \Phi \\
H_{\mathrm{p}}(10, \alpha) / \Phi=\mathrm{Q} \times \mathrm{K}(10, \alpha) / \Phi\end{array}$} & D: Absorbed dose & \multirow{4}{*}{1} & \multirow{4}{*}{$\begin{array}{c}\text { From } \\
0.015 \text { to } 10 \mathrm{MeV}\end{array}$} & $\mathrm{pSv} \cdot \mathrm{cm}^{2}$ \\
\hline & & K: Kerma approximations & & & $\mathrm{pSv} \cdot \mathrm{cm}^{2}$ \\
\hline & \multirow{2}{*}{$\begin{array}{l}H_{\mathrm{p}}(10, \alpha) / \mathrm{K}_{\mathrm{air}}=\mathrm{Q} \times \mathrm{D}(10, \alpha) / \mathrm{K}_{\mathrm{air}} \\
H_{\mathrm{p}}(10, \alpha) / \mathrm{K}_{\mathrm{air}}=\mathrm{Q} \times \mathrm{K}(10, \alpha) / \mathrm{K}_{\mathrm{air}}\end{array}$} & $\mathrm{D}:$ Absorbed dose & & & Sv/Gy \\
\hline & & K: Kerma approximations & & & Sv/Gy \\
\hline
\end{tabular}


The relative differences with is calculated by EGSnrc code and reference ICRU-57 has given by relation in the following:

Relative difference $=\frac{\text { Abs (Calculated Value }- \text { Reference Value })}{\text { Reference Value }} \%$

Eq. 3

The relative differences between obtained results and the value of ICRU-57 less than 3\%, except at the low energy the relative differences more than $3 \%$.

\section{Conversion coefficients by analytical fits}

In this work, we suggest a new equation to perform an analytical fit of our Monte Carlo calculated conversion coefficients for photons $H_{p}(10)$ for different angles. The new analytical fit has been based on non-linear least squares Levenberg-Marquardt algorithm to calculate the parameters. The new analytical Method of a non-linear least squares Levenberg-Marquardt algorithm has been applied for calculating the parameter of Equation 4. The Tables 2-6 show the fitting parameter of the analytical Method a non-linear least square. Equation 4 has been validated to calculate the conversion coefficients [15].

$f(x)=\frac{a_{1} x^{5}+a_{2} x^{4}+a_{3} x^{3}+a_{4} x^{2}+a_{5} x+a_{6}}{x^{5}+b_{1} x^{4}+b_{2} x^{3}+b_{3} x^{2}+b_{4} x+b_{5}}$

Eq. 4

where:

$f(x)$ is the conversion coefficients.

$\mathrm{x}$ is energy, with Energy in $\mathrm{MeV}$.

$a_{i}, b_{j}(i=1,2, . .6$ and $j=1,2, . .5)$, are the parameter fitting non-linear least squares Levenberg-Marquardt algorithm of conversion coefficients. The parameters of the analytical fit are summarized in Tables 2-6.

\section{Results and discussion}

\section{Air-Kerma calculations}

The conversion coefficients relate protection or operational quantity to radiometric or dosimetric quantities. They are given to the operational quantities from the radiometric and dosimetric quantities fluence or air kerma. The air Kerma in air is calculated as a measurable reference quantity for photon metrology [16]. Air Kerma has been calculated using the analytical method, Equation 5 and EGSnrc code. The $\mathrm{K}_{\text {air }} / \Phi$ $\left(\mathrm{pGy} \cdot \mathrm{cm}^{2}\right)$ values can be calculated from the mass-energy transfer coefficients $\left(\mu_{\mathrm{tr}} / \rho\right)$ by stratifying the following Equation 5 [16-18]:

$\frac{K_{\text {air }}}{\Phi}=E \frac{\mu_{t r}}{\rho}$

Where is the mass-energy transfer coefficients in $\left(\mathrm{cm}^{2} / \mathrm{g}\right), \mathrm{E}$ is the photon energy in Joule.

The results obtained by EGSnrc code, Calculation by Equation 5 and analytical fit are identical with the comparison to those reports CEA-R-6235 [16] and ICRU 57 [14], Figure 2 and Table 7.

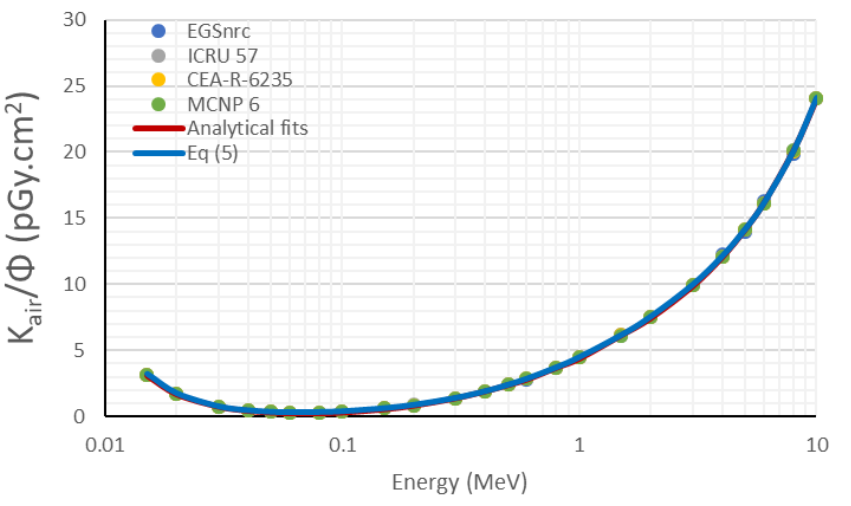

Figure 2. $\mathrm{K}_{\mathrm{air}} / \Phi\left(\mathrm{pGy} \cdot \mathrm{cm}^{2}\right)$ values calculated with EGSnrc code, ICRU 57, CEA-R-6235, analytical fit and calculation by Equation 5 from 0.015 to $10 \mathrm{MeV}$.

The statistical uncertainty associated with EGSnrc code for low photon energy less than $0.2 \%$, and for high photon energy less than $0.3 \%$.

\section{Conversion coefficients from fluence to personal dose equivalent $H_{\mathrm{p}}(10, \alpha) / \Phi$}

The calculation of the conversion coefficients has been carried out in two modes: absorbed dose Kerma approximation. The values of $H_{\mathrm{p}}(10, \alpha) / \Phi$ in $\mathrm{pSv} \cdot \mathrm{cm}^{2}$ for energies from $15 \mathrm{keV}$ to $10 \mathrm{MeV}$ angles of incidence from $0^{\circ}$ to a $75^{\circ}$ in steps of $15^{\circ}$.

The following curves (Figures 3-8) represent the data of the conversion coefficients $H_{\mathrm{p}}(10, \alpha) / \Phi$ in $\mathrm{pSv} \cdot \mathrm{cm}^{2}$, calculated using EGSnrc code, analytical approaches and those published at ICRU 57 in term pf Kerma approximation and in terms of absorbed dose according to the angle incidence. The values of $H_{\mathrm{p}}(10, \alpha) / \Phi$ summarized in Tables 8-9 in absorbed dose term and in Tables 10-12 in approximation Kerma (Appendix).

$H_{\mathrm{p}}(10, \alpha) / \Phi$ values are increased for photon energies from $15 \mathrm{keV}$ to about $20 \mathrm{keV}$ owning to the decreasing of the transmission factor that the energy increases in this area where the preponderant interaction is photoelectric. At $20 \mathrm{keV}$, the curve reaches a maximum before bending and decreasing odorant interaction is the Compton type. The energy of the photon incident is strong, the higher the one carried by the electron Compton is on average high, the energy yielded in the medium grows so as the energy increases [16].

For low photons energies, when the angle of incidence $\alpha$ increases, consequently the distance increases to interest point, so it absorbs energy before it reaches the point of interest, the dose absorbed may be under $10 \mathrm{~mm}$ the curve of conversion coefficients is low Figures 3-8 [16]. For high photons energies, this Compton scattering becomes significant and the incident beam attenuation less important. The scattered photon contributes to the increase of the dose at the measurement point under $10 \mathrm{~mm}$ and compensates for the attenuation of the primary beam [16]. 


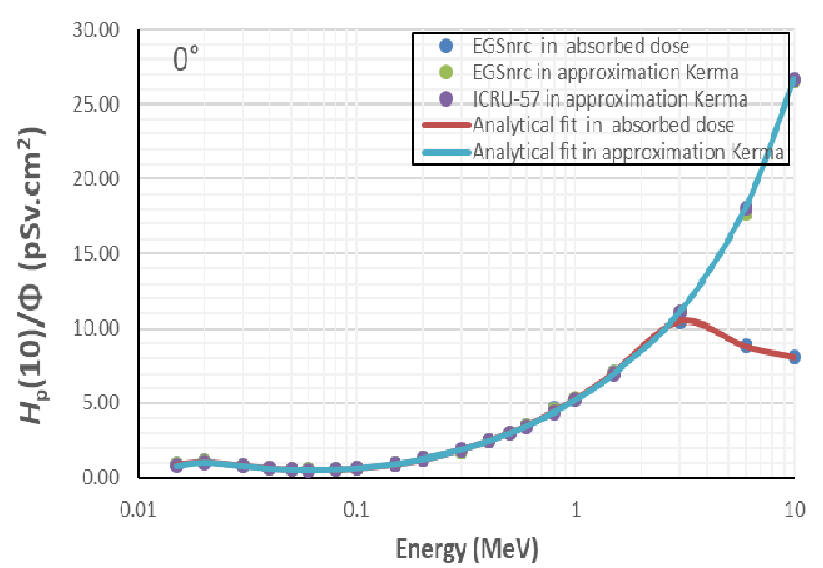

Figure 3. Conversion coefficients from photon fluence to personal dose equivalent for $0^{\circ}$ incident angle.

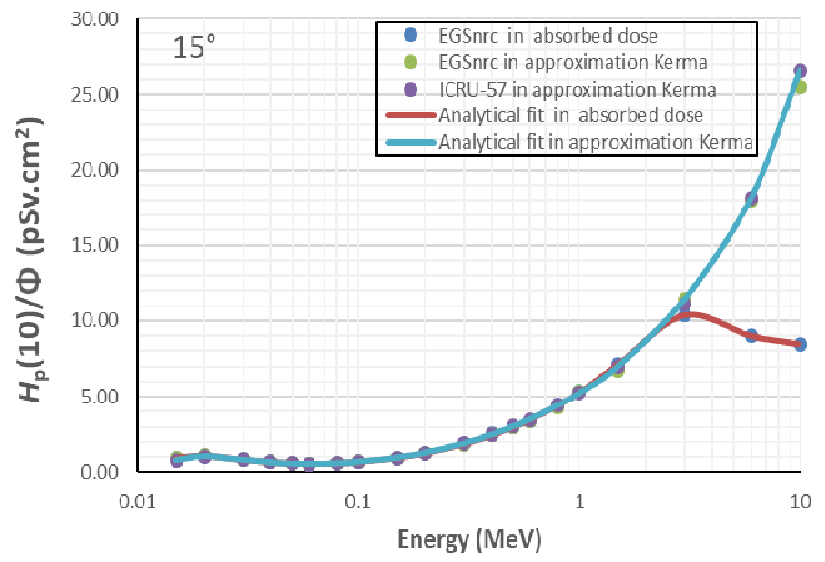

Figure 4. Conversion coefficients from photon fluence to personal dose equivalent for $15^{\circ}$ incident angle.

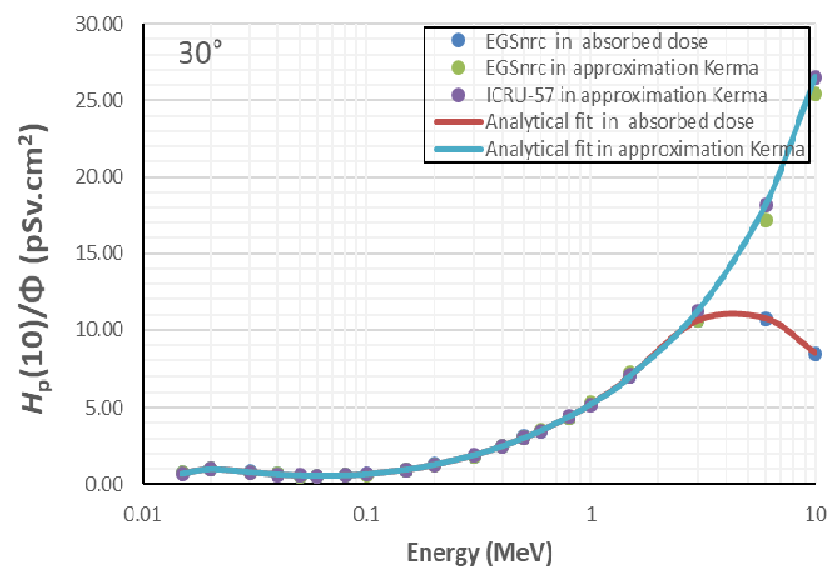

Figure 5. Conversion coefficients from photon fluence to personal dose equivalent for $30^{\circ}$ incident angle.

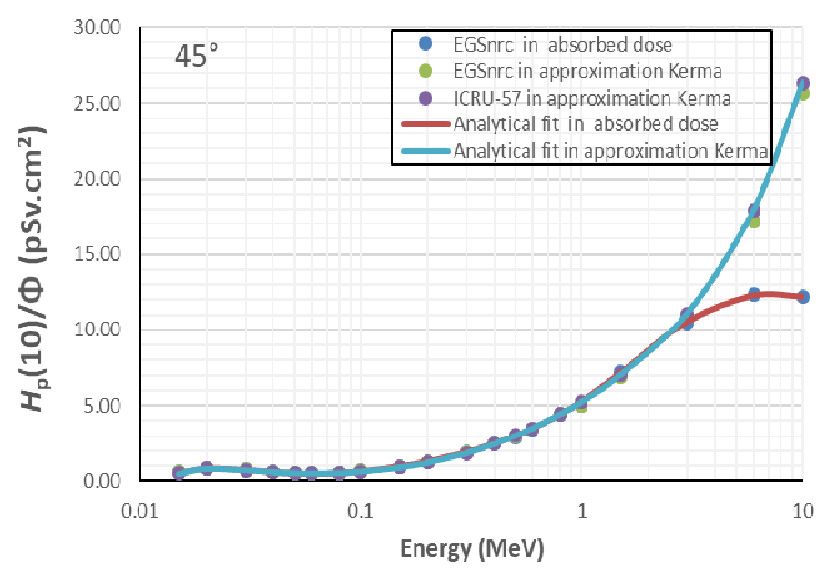

Figure 6. Conversion coefficients from photon fluence to personal dose equivalent for $45^{\circ}$ incident angle.

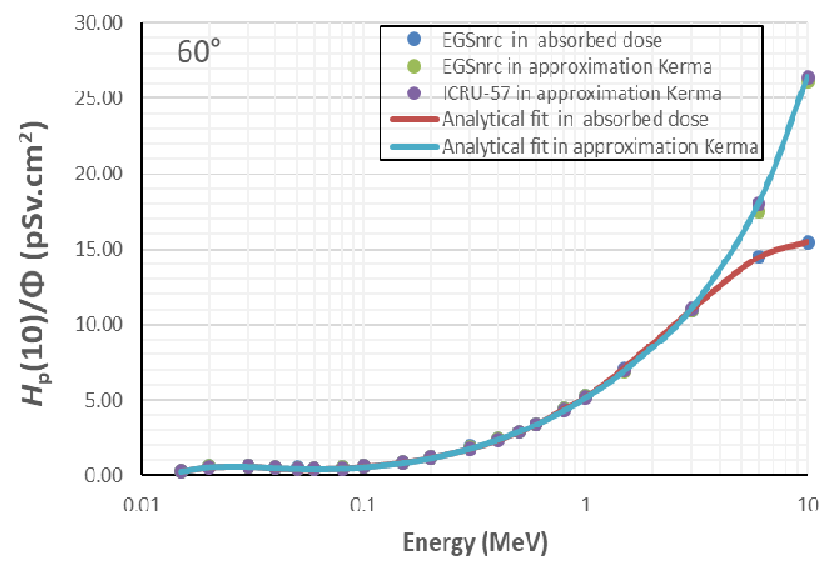

Figure 7. Conversion coefficients from photon fluence to personal dose equivalent for $60^{\circ}$ incident angle.

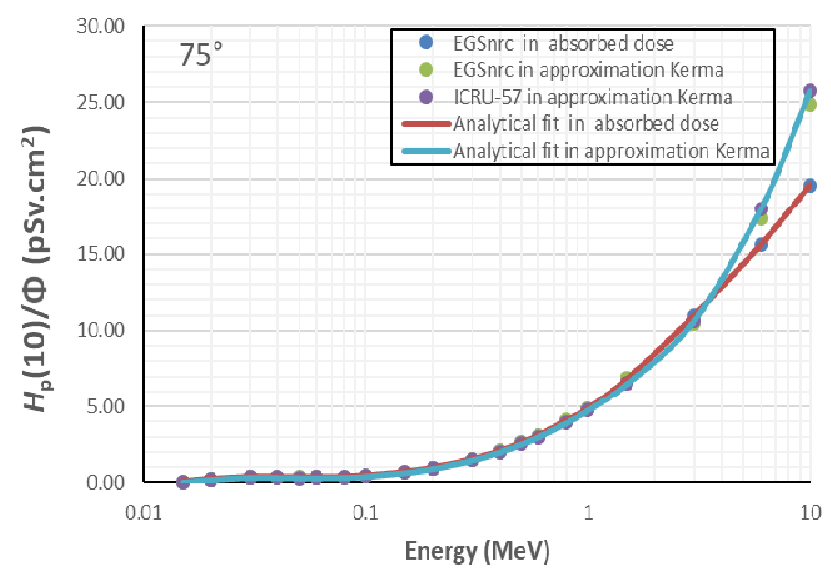

Figure 8. Conversion coefficients from photon fluence to personal dose equivalent for $75^{\circ}$ incident angle. 


\section{Conversion coefficients from air Kerma to personal dose equivalent $H_{\mathrm{p}}(10, \alpha) / K_{\text {air }}$}

In this part, the Figures 9-14 represent the values of the conversion coefficients, $H_{\mathrm{p}}(10, \alpha) / \mathrm{K}_{\mathrm{air}}$ in $(\mathrm{Sv} / \mathrm{Gy})$ calculated using, method of analytical, EGSnrc code and compared with

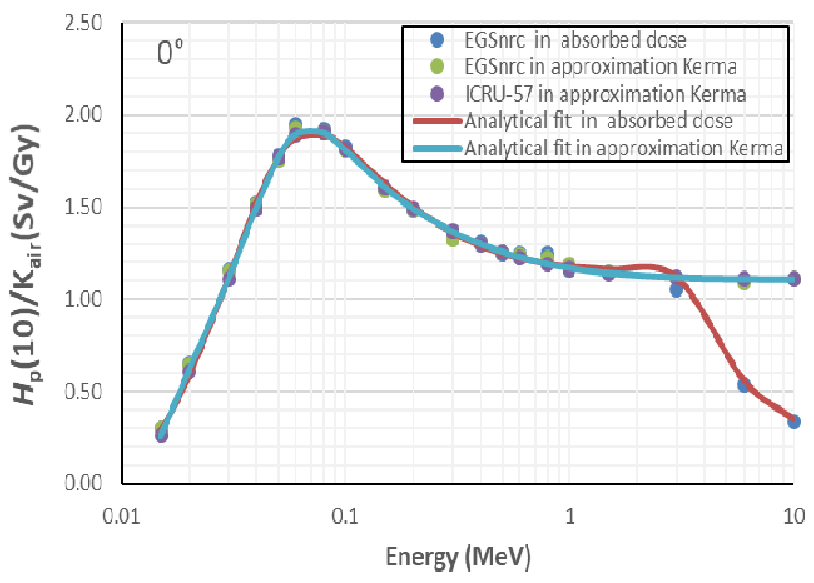

Figure 9. Conversion coefficients from photon air Kerma to personal dose equivalent for $0^{\circ}$ incident angle.

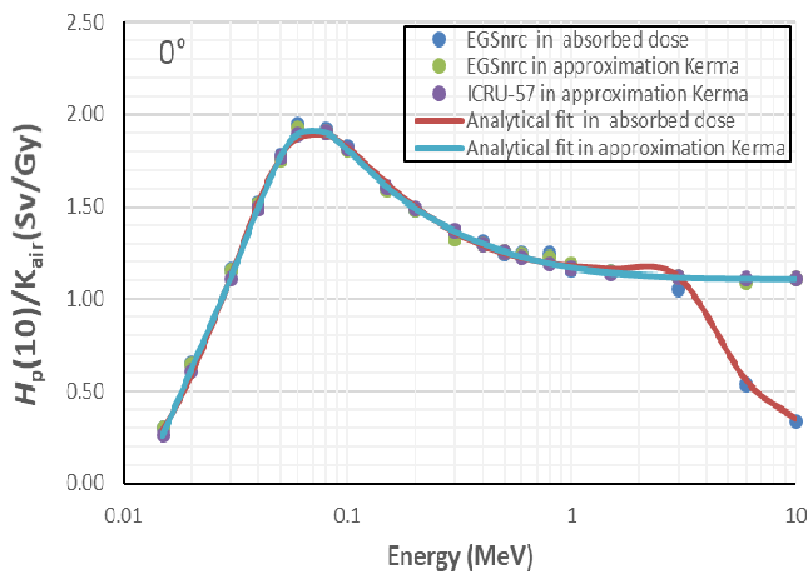

Figure 10. Conversion coefficients from photon air Kerma to personal dose equivalent for $15^{\circ}$ incident angle.

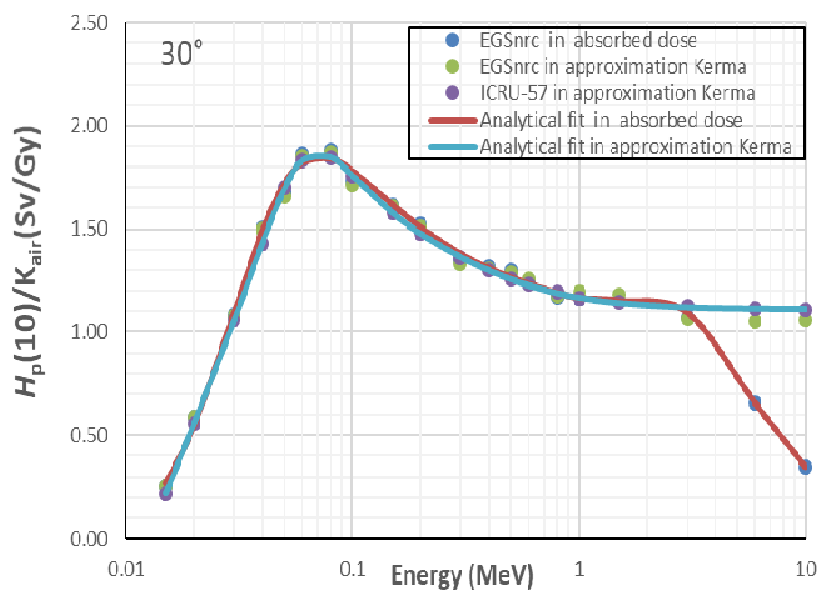

Figure 11. Conversion coefficients from photon air Kerma to personal dose equivalent for $30^{\circ}$ incident angle. those published at ICRU57 in terms of Kerma approximation and in term of absorbed dose according to the angle incidence from $0^{\circ}$ to a $75^{\circ}$ in steps of $15^{\circ}$, are summarized in Tables 13 14 for the term of absorbed dose and Tables 15-17 for approximation-Kerma (Appendix).

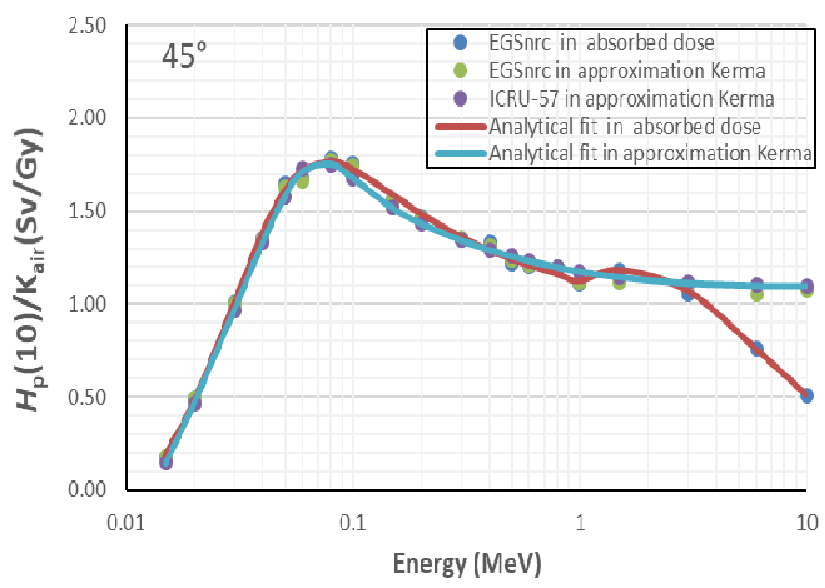

Figure 12. Conversion coefficients from photon air Kerma to personal dose equivalent for $45^{\circ}$ incident angle.

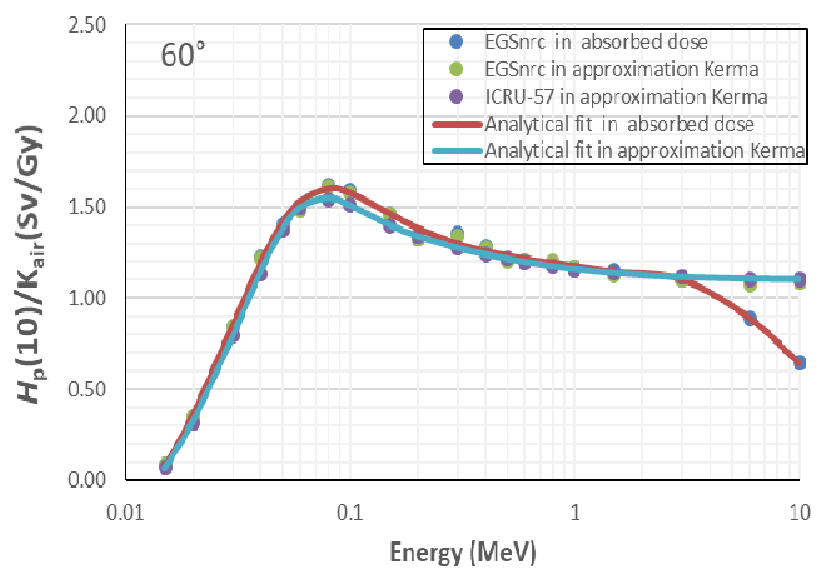

Figure 13. Conversion coefficients from photon air Kerma to personal dose equivalent for $60^{\circ}$ incident angle.

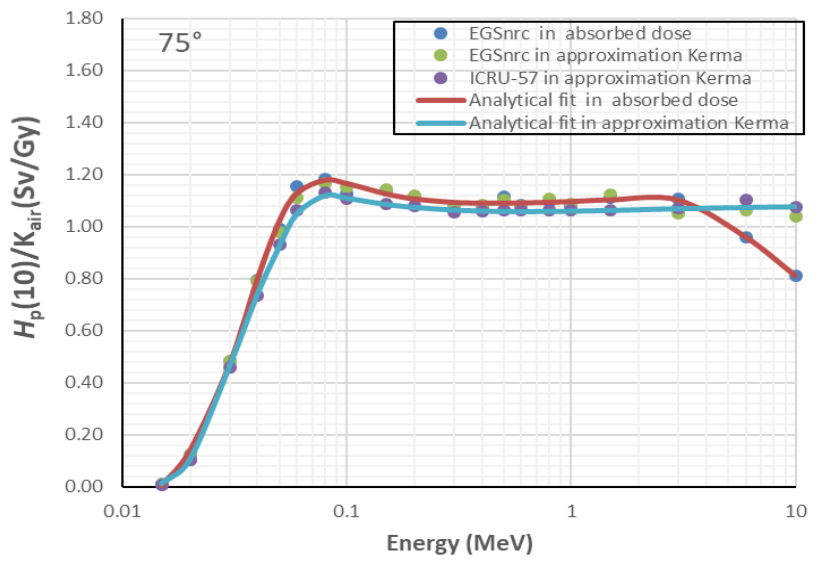

Figure 14. Conversion coefficients from photon air Kerma to personal dose equivalent for $75^{\circ}$ incident angle. 
In two terms, whenever increasing the angle of incidence, the conversion coefficients values are decreasing up to $3 \mathrm{MeV}$, due to the long distance between the source and volume interest (depth $10 \mathrm{~mm}$ ), so, the secondary electron loses energy there before reaching depth $10 \mathrm{~mm}$. Above energies of $3 \mathrm{MeV}$, there are two cases: The first case, in absorbed dose mode, for low angles incidence and high energies the $H_{\mathrm{p}}(10, \alpha)$ values are decreasing, owing the high energies are not the interactions in volume interest or the secondary electrons are deposing their energy outside the point interest. The second case, in Kerma approximations for low angles incidence and high energies the conversion coefficients stabilizes around unity, owing to the achievement of the equilibrium electronic (Figures 9-14).

The peak of $H_{\mathrm{p}}(10, \alpha) / \mathrm{K}_{\text {air }}$ conversion coefficients is found between $60 \mathrm{keV}$ and $100 \mathrm{keV}$, photon energies that produce the highest quantities of large scattering angles and the dose maximum may be at depth $10 \mathrm{~mm}$ [19]. For energies higher than $600 \mathrm{keV}$ the conversion coefficients stabilize around 1 owing to the obtain of the equilibrium electronic [10,20-21]. Generally, as beam angle increases, conversion coefficients decrease in low energies due to the escape of the secondary electrons away at the volume interest. So, the low energies $(<3$ $\mathrm{MeV}$ ) their highest influence on the effective dose (depth 10 $\mathrm{mm})$. Above about $3 \mathrm{MeV}$, in approximations Kerma the conversion coefficients are quite similar to all angle incidences, and in absorbed dose mode the conversion coefficients decrease more with small-angle at depth $10 \mathrm{~mm}$. We can also say that the Kerma approximation has more effects at high photon energies (> $3 \mathrm{MeV}$ ), compared to the absorbed dose, which has no effect at depth $10 \mathrm{~mm}$.
In the report ICRU 57, the conversion coefficients were calculated in Kerma approximations, the numerical value of Kerma approaches that of the absorbed dose, to the degree that charged-particle equilibrium (CPE) exists, that radiative losses are negligible [6]. In this work the simulations to calculate the personal dose equivalent $H_{\mathrm{p}}(10, \alpha)$ consisted of two parts: Kerma approximations and absorbed dose calculation were performed within each volume of interest, on the basis that radiative losses exist in high energy.

It's clear $H_{\mathrm{p}}(10, \alpha) / \Phi$ curves are matched between Dose mode and Kerma from $0^{\circ}$ to $75^{\circ}$, up $3 \mathrm{MeV}$, woing the numerical value of Kerma access that of the absorbed dose, to the degree that charged-particle equilibrium (CPE) exists. Above high energies (> $3 \mathrm{MeV}$ ) the difference is large between them in the angles from $0^{\circ}$ to $30^{\circ}$, Figures 7-9, but the angles from $45^{\circ}$ to $75^{\circ}$, Figures 10-12 are found the variation a low degree because of the lack of electronic equilibrium.

\section{Conclusions}

The conversion coefficients have been calculated for monoenergetic photons from 0.015 to $10 \mathrm{MeV}$ in the absorbed dose and Kerma-approximations using analytical fits and MC. Our computed values agree well when compared with those published for the ICRU 57 in Kerma approximations. The $H_{\mathrm{p}}(10, \alpha)$ values for photons have validated by Analytical fit and EGSnrc code. We can conclude a new analytical fit provides a convenient approach for determining conversion coefficients.

\section{References}

[1] El Bardouni T, Mohammed M, Chakir E, et al. Conversion coefficients for photon exposure of the human lens eye: EGSnrc and MCNP6 Monte Carlo simulation. Radiat Phys Chem. 2019;156:159-168.

[2] Wernli C. External Dosimetry: Operational Quantities and their Measurement. 11th International Congress of the International Radiation Protection Association (IRPA), Madrid, 2004.

[3] Zhang B, Dang B, Wang Z, et al. The local skin dose conversion coefficients of electrons, protons and alpha particles calculated using the Geant4 code. Radiat Prot Dosimetry. 2013;156(4):514-517.

[4] Rosado PHG, Nogueira MS, Genezini F, Vilela EC. Measurement of conversion coefficients between free in air kerma and personal dose equivalent for diagnostic X-ray beams. Radiat Meas. 2008;43(2-6):968-971.

[5] Al Kanti H, El Hajjaji O, El Bardouni T. Personal Dose Equivalent Conversion Coefficients Skins Dose for Mono-Energetic Photons, Electrons, and Positrons: Monte Carlo Approach and Development of an Analytical Approach. Moscow Univ Phys Bull. 2019;74(5):520-528.

[6] Petoussi-Henss N, Bolch WE, Eckerman KF, et al. Conversion Coefficients for Radiological Protection Quantities for External Radiation Exposures. Ann ICRP;2010;40(2-5):1-257.

[7] Institut de Radioprotection et de Sûreté Nucléaire (IRSN). Publication 103 de la CIPR. Recommandations 2007 de la Commission internationale de protection radiologique. 2009.

[8] Daures J, Gouriou J, Bordy JM. Monte Carlo determination of the conversion coefficients $H_{\mathrm{p}}(3) / \mathrm{K}_{\mathrm{a}}$ in a right cylinder phantom with "PENELOPE" code. Comparison with "MCNP" simulations. Radiat Prot Dosimetry. 2011;144(1-4):37-42.

[9] Hörnlund M. Estimation of dose conversion factors. Conversion factors from measurable to risk related quatities. Master Sci Thesis. Lund University and University of Gothenburg. 2013. 
[10] Rogers DQO, Kawrakow I, Seuntjens JP, et al. Technical Report PIRS-702: NRC User Codes for EGSnrc. National Research Council Canada, Ottawa, Canada. 2017.

[11] Kim JH, Hill R, Kuncic Z. An evaluation of calculation parameters in the EGSnrc/BEAMnrc Monte Carlo codes and their effect on surface dose calculation. Phys Med Biol. 2012;57(14):N267-N278.

[12] Kawrakow I, Mainegra-Hing E, Rogers DWO, et al. Technical Report PIRS-701. The EGSnrc Code System: Monte Carlo Simulation of Electron and Photon Transport. National Research Council Canada, Ottawa, Canada. 2017.

[13] ICRP. Conversion Coefficients for use in Radiological Protection against External Radiation. ICRP Publication 74 . Ann ICRP. 1996;26(3-4).

[14] ICRU Report 57. Conversion Coefficients for use in Radiological Protection Against External Radiation. 1997.

[15] Al Kanti A, El Hajjaji O, El Bardouni T, Mohammed M. An analytical fit and EGSnrc code (MC) calculations of personal dose equivalent conversion coefficients for mono-energetic electrons. Appl Radiat Isot. 2019;154:108906.

[16] Antoni R, Bourgois L. Physique appliquée à l'exposition externe: Dosimétrie et radioprotection. Springer, 2013.

[17] Mayles P, Nahum A, Rosenwald C. Handbook of Radiotherapy Physics: Theory and Practice. 2007.

[18] Al Kanti H, El Hajjaji O, El Bardouni T, et al. Conversion coefficients calculation of mono-energetic photons from air-kerma using Monte Carlo and analytical methods. J King Saud Univ - Sci. 2018;32(1):288-293.

[19] Lienard A. Organ dose conversion coefficients for pediatric reference computational phantoms in external photon radiation fields. Thesis. Georgetown University. 2015.

[20] Attix FH. Introduction to Radiological Physics and Radiation Dosimetry. Wiley-VCH. 1986.

[21] Attix FH. Comparison of Monte Carlo and analytical calculations of average dose deposited in aluminum foils by broad beams of electrons. Int J Radiat Appl Instrumentation. Part A. Appl Radiat Isot. 1991:42(10):953-964. 


\section{Appendix}

Table 2. Coefficients Fitting non-linear least squares Levenberg-Marquardt algorithm of conversion coefficients for air Kerma.

\begin{tabular}{cc}
\hline \hline parameter & Air Kerma \\
\hline a1 & $3.7990 \mathrm{E}+05$ \\
a2 & $8.3140 \mathrm{E}+05$ \\
a3 & $-2.8900 \mathrm{E}+06$ \\
a4 & $1.6580 \mathrm{E}+06$ \\
a5 & $-1.5240 \mathrm{E}+05$ \\
a6 & $6.1220 \mathrm{E}+03$ \\
b1 & $2.0280 \mathrm{E}+05$ \\
b2 & $-1.9440 \mathrm{E}+05$ \\
b3 & $-2.1920 \mathrm{E}+05$ \\
b4 & $1.7420 \mathrm{E}+05$ \\
b5 & $-1.2160 \mathrm{E}+03$ \\
\hline \hline
\end{tabular}

Table 3. Parameter Fitting of conversion coefficients for $H_{\mathrm{p}}(10, \alpha) / \Phi$ for photons from $0^{\circ}$ to $75^{\circ}$ in terms of absorbed dose.

\begin{tabular}{|c|c|c|c|c|c|c|}
\hline \multirow{2}{*}{$\begin{array}{c}\text { Angles } \\
\text { Parameter } \\
\end{array}$} & \multicolumn{6}{|c|}{ Conversion coefficients from photon fluence in terms of absorbed dose. } \\
\hline & $\mathbf{0}^{\circ}$ & $15^{\circ}$ & $30^{\circ}$ & $45^{\circ}$ & $60^{\circ}$ & $75^{\circ}$ \\
\hline a1 & $8.813 \mathrm{E}+00$ & $9.052 \mathrm{E}+00$ & $5.220 \mathrm{E}+00$ & $9.945 \mathrm{E}+00$ & $-8.519 \mathrm{E}+06$ & $2.637 \mathrm{E}+01$ \\
\hline $\mathrm{a} 2$ & $-5.664 \mathrm{E}+01$ & $-4.603 \mathrm{E}+01$ & 8.184E-01 & $5.323 \mathrm{E}+01$ & $3.853 \mathrm{E}+08$ & $-3.041 \mathrm{E}+02$ \\
\hline a3 & $1.741 \mathrm{E}+02$ & $1.400 \mathrm{E}+02$ & $1.632 \mathrm{E}+02$ & $1.691 \mathrm{E}+01$ & $-3.467 \mathrm{E}+08$ & $2.860 \mathrm{E}+02$ \\
\hline $\mathrm{a} 4$ & $-1.275 \mathrm{E}+01$ & $-8.938 \mathrm{E}+00$ & $-1.222 \mathrm{E}+01$ & $-1.827 \mathrm{E}+00$ & $2.212 \mathrm{E}+07$ & $-2.445 \mathrm{E}+01$ \\
\hline a5 & 7.749E-01 & $5.496 \mathrm{E}-01$ & 7.328E-01 & $9.612 \mathrm{E}-02$ & $-8.972 \mathrm{E}+05$ & $1.216 \mathrm{E}+00$ \\
\hline a6 & $-7.217 \mathrm{E}-03$ & $-5.238 \mathrm{E}-03$ & $-7.583 \mathrm{E}-03$ & -9.440 E-04 & $7.396 \mathrm{E}+03$ & $-1.301 \mathrm{E}-02$ \\
\hline b1 & $-4.815 \mathrm{E}+00$ & $-3.719 \mathrm{E}+00$ & $-3.628 \mathrm{E}+00$ & $1.468 \mathrm{E}+00$ & $1.329 \mathrm{E}+07$ & $-7.364 \mathrm{E}+00$ \\
\hline $\mathrm{b} 2$ & $6.683 \mathrm{E}+00$ & $4.404 \mathrm{E}+00$ & $1.579 \mathrm{E}+01$ & $1.135 \mathrm{E}+01$ & $4.343 \mathrm{E}+07$ & $-3.660 \mathrm{E}+01$ \\
\hline b3 & $1.906 \mathrm{E}+01$ & $1.656 \mathrm{E}+01$ & $1.730 \mathrm{E}+01$ & 9.912E-01 & $-4.855 \mathrm{E}+07$ & $4.111 \mathrm{E}+01$ \\
\hline b4 & $-3.068 \mathrm{E}-01$ & $-2.928 \mathrm{E}-01$ & $-2.558 \mathrm{E}-01$ & $-9.538 \mathrm{E}-03$ & $1.726 \mathrm{E}+06$ & $-1.261 \mathrm{E}+00$ \\
\hline b5 & $2.575 \mathrm{E}-03$ & $2.243 \mathrm{E}-03$ & $1.674 \mathrm{E}-03$ & $1.902 \mathrm{E}-04$ & $-2.358 \mathrm{E}+04$ & 2.691E-02 \\
\hline
\end{tabular}

Table 4. Parameter Fitting of conversion coefficients for $H_{\mathrm{p}}(10, \alpha) / \Phi$ for photons from $0^{\circ}$ to $75^{\circ}$ in terms of approximation Kerma.

\begin{tabular}{|c|c|c|c|c|c|c|}
\hline \multirow{2}{*}{$\begin{array}{c}\text { Angles } \\
\text { Parameter }\end{array}$} & \multicolumn{6}{|c|}{ Conversion coefficients from photon fluence in terms of approximations Kerma } \\
\hline & $\mathbf{0}^{\circ}$ & $15^{\circ}$ & $30^{\circ}$ & $45^{\circ}$ & $60^{\circ}$ & $75^{\circ}$ \\
\hline a1 & $-8.515 \mathrm{E}+02$ & $-2.689 \mathrm{E}+05$ & $7.730 \mathrm{E}+03$ & $7.430 \mathrm{E}+05$ & $2.785 \mathrm{E}+01$ & $6.393 \mathrm{E}+01$ \\
\hline $\mathrm{a} 2$ & $-1.816 \mathrm{E}+03$ & $-4.767 \mathrm{E}+05$ & $3.910 \mathrm{E}+04$ & $1.804 \mathrm{E}+06$ & $8.920 \mathrm{E}+01$ & $-1.196 \mathrm{E}+02$ \\
\hline a3 & $1.235 \mathrm{E}+04$ & $3.855 \mathrm{E}+06$ & $-2.227 \mathrm{E}+02$ & $-6.931 E+06$ & $3.221 \mathrm{E}+03$ & $5.371 \mathrm{E}+02$ \\
\hline a4 & $-8.162 \mathrm{E}+02$ & $-2.573 E+05$ & $-7.538 \mathrm{E}+01$ & $5.502 \mathrm{E}+05$ & $-2.594 \mathrm{E}+02$ & $-4.956 \mathrm{E}+01$ \\
\hline a5 & $4.750 \mathrm{E}+01$ & $1.451 \mathrm{E}+04$ & $1.320 \mathrm{E}+01$ & $-3.342 \mathrm{E}+04$ & $1.433 \mathrm{E}+01$ & $2.532 \mathrm{E}+00$ \\
\hline a6 & $-4.473 \mathrm{E}-01$ & $-1.324 \mathrm{E}+02$ & $-1.675 \mathrm{E}-01$ & $3.616 \mathrm{E}+02$ & $-1.449 \mathrm{E}-01$ & $-2.798 \mathrm{E}-02$ \\
\hline b1 & $-4.404 E+02$ & $-1.337 \mathrm{E}+05$ & $3.883 \mathrm{E}+03$ & $3.700 \mathrm{E}+05$ & $-9.943 E+00$ & $1.161 \mathrm{E}+01$ \\
\hline b2 & 7.467E+02 & $2.474 \mathrm{E}+05$ & $4.928 \mathrm{E}+03$ & $-3.864 \mathrm{E}+05$ & $2.199 \mathrm{E}+02$ & $-2.035 \mathrm{E}+00$ \\
\hline b3 & $1.428 \mathrm{E}+03$ & $4.434 \mathrm{E}+05$ & $9.292 \mathrm{E}+01$ & $-7.268 \mathrm{E}+05$ & $3.941 \mathrm{E}+02$ & $8.316 \mathrm{E}+01$ \\
\hline b4 & $-2.883 \mathrm{E}+01$ & $-9.354 \mathrm{E}+03$ & $2.363 \mathrm{E}+00$ & $7.501 \mathrm{E}+03$ & $-8.179 \mathrm{E}+00$ & $-2.626 \mathrm{E}+00$ \\
\hline b5 & $2.589 \mathrm{E}-01$ & $9.009 \mathrm{E}+01$ & $-5.134 \mathrm{E}-02$ & $-3.120 \mathrm{E}+01$ & $1.199 \mathrm{E}-01$ & $5.770 \mathrm{E}-02$ \\
\hline
\end{tabular}


Table 5. Parameter Fitting of conversion coefficients for $H_{\mathrm{p}}(10, \alpha) / \mathrm{K}_{\mathrm{air}}$ for photons from $0^{\circ}$ to $75^{\circ}$ in terms of absorbed dose.

\begin{tabular}{|c|c|c|c|c|c|c|}
\hline \multirow{2}{*}{$\begin{array}{c}\text { Angles } \\
\text { Parameter } \\
\end{array}$} & \multicolumn{6}{|c|}{ Conversion coefficients from photon Air Kerma in terms of absorbed dose. } \\
\hline & $\mathbf{0}^{\circ}$ & $15^{\circ}$ & $30^{\circ}$ & $45^{\circ}$ & $60^{\circ}$ & $75^{\circ}$ \\
\hline a1 & $6.87 \mathrm{E}-01$ & 8.79E-01 & $-1.54 \mathrm{E}+04$ & $-1.06 \mathrm{E}+05$ & $3.93 \mathrm{E}+00$ & $8.93 \mathrm{E}-01$ \\
\hline $\mathrm{a} 2$ & $-9.56 \mathrm{E}+00$ & $-1.33 \mathrm{E}+01$ & $3.01 \mathrm{E}+05$ & $2.43 \mathrm{E}+06$ & $-8.26 \mathrm{E}+01$ & $-1.04 \mathrm{E}+01$ \\
\hline a3 & $3.85 \mathrm{E}+01$ & $5.15 \mathrm{E}+01$ & $-1.21 \mathrm{E}+06$ & $-9.24 \mathrm{E}+06$ & $2.18 \mathrm{E}+02$ & $5.04 \mathrm{E}+01$ \\
\hline $\mathrm{a} 4$ & $1.26 \mathrm{E}+00$ & $1.41 \mathrm{E}+00$ & $1.36 \mathrm{E}+06$ & $8.24 \mathrm{E}+06$ & $7.44 \mathrm{E}+00$ & $-1.14 \mathrm{E}+00$ \\
\hline a5 & $-3.55 \mathrm{E}-02$ & $4.57 \mathrm{E}-02$ & $5.60 \mathrm{E}+04$ & $4.56 \mathrm{E}+05$ & $1.89 \mathrm{E}+00$ & $8.45 \mathrm{E}-02$ \\
\hline a6 & $1.58 \mathrm{E}-04$ & $-7.16 \mathrm{E}-04$ & $-6.50 \mathrm{E}+02$ & $-6.23 E+03$ & $-2.81 \mathrm{E}-02$ & $-1.17 \mathrm{E}-03$ \\
\hline b1 & $-1.04 \mathrm{E}+01$ & $-1.29 \mathrm{E}+01$ & $2.02 \mathrm{E}+05$ & $1.75 \mathrm{E}+06$ & $-6.18 \mathrm{E}+01$ & $-1.03 \mathrm{E}+01$ \\
\hline $\mathrm{b} 2$ & $3.74 \mathrm{E}+01$ & $4.84 \mathrm{E}+01$ & $-1.01 \mathrm{E}+06$ & $-8.01 E+06$ & $1.82 \mathrm{E}+02$ & $4.64 \mathrm{E}+01$ \\
\hline b3 & $-1.91 \mathrm{E}+00$ & $-2.11 \mathrm{E}+00$ & $1.27 \mathrm{E}+06$ & $8.03 \mathrm{E}+06$ & $4.74 \mathrm{E}+00$ & $-7.55 \mathrm{E}-01$ \\
\hline b4 & $9.38 \mathrm{E}-02$ & $1.12 \mathrm{E}-01$ & $-4.09 \mathrm{E}+04$ & $-2.11 \mathrm{E}+05$ & $2.84 \mathrm{E}-01$ & $-2.93 \mathrm{E}-02$ \\
\hline b5 & $-9.63 \mathrm{E}-04$ & $2.67 \mathrm{E}-04$ & $2.14 \mathrm{E}+03$ & $1.38 \mathrm{E}+04$ & $3.08 \mathrm{E}-02$ & $3.96 \mathrm{E}-03$ \\
\hline
\end{tabular}

Table 6. Parameter Fitting of conversion coefficients for $H_{\mathrm{p}}(10, \alpha) / \mathrm{K}_{\text {air }}$ for photons from $0^{\circ}$ to $75^{\circ}$ in terms of approximation Kerma.

\begin{tabular}{|c|c|c|c|c|c|c|}
\hline \multirow{2}{*}{$\begin{array}{c}\text { Angles } \\
\text { Parameter } \\
\end{array}$} & \multicolumn{6}{|c|}{ Conversion coefficients from photon Air Kerma in terms of approximations Kerma. } \\
\hline & $\mathbf{0}^{\circ}$ & $15^{\circ}$ & $30^{\circ}$ & $45^{\circ}$ & $60^{\circ}$ & $\mathbf{7 5}^{\circ}$ \\
\hline a1 & $1.11 \mathrm{E}+00$ & $1.11 \mathrm{E}+00$ & $1.11 \mathrm{E}+00$ & $4.93 \mathrm{E}+01$ & $1.10 \mathrm{E}+00$ & $1.08 \mathrm{E}+00$ \\
\hline $\mathrm{a} 2$ & $1.78 \mathrm{E}+00$ & $-2.58 \mathrm{E}-01$ & $3.08 \mathrm{E}-01$ & $3.12 \mathrm{E}+04$ & $4.97 \mathrm{E}+00$ & 9.81E-01 \\
\hline a3 & $3.94 \mathrm{E}-01$ & $2.31 \mathrm{E}-01$ & $1.83 \mathrm{E}-01$ & $3.78 \mathrm{E}+03$ & 8.03E-01 & $-1.44 \mathrm{E}-01$ \\
\hline a4 & $-2.34 \mathrm{E}-02$ & $-1.13 \mathrm{E}-02$ & $-1.42 \mathrm{E}-02$ & $-5.42 \mathrm{E}+02$ & $-3.50 \mathrm{E}-02$ & 7.22E-03 \\
\hline a5 & $1.38 \mathrm{E}-03$ & 7.73E-04 & 8.83E-04 & $4.58 \mathrm{E}+01$ & $6.81 \mathrm{E}-03$ & $-1.28 \mathrm{E}-04$ \\
\hline $\mathrm{a} 6$ & $-1.43 \mathrm{E}-05$ & $-8.19 \mathrm{E}-06$ & $-9.18 \mathrm{E}-06$ & $-5.12 \mathrm{E}-01$ & $-8.92 \mathrm{E}-05$ & 7.37E-07 \\
\hline b1 & $1.64 \mathrm{E}+00$ & $-2.65 \mathrm{E}-01$ & $2.64 \mathrm{E}-01$ & $2.91 \mathrm{E}+04$ & $4.54 \mathrm{E}+00$ & $9.58 \mathrm{E}-01$ \\
\hline b2 & $1.71 \mathrm{E}-01$ & $1.92 \mathrm{E}-01$ & $1.03 \mathrm{E}-01$ & $2.86 \mathrm{E}+02$ & $3.60 \mathrm{E}-01$ & $-1.50 \mathrm{E}-01$ \\
\hline b3 & $-1.66 \mathrm{E}-02$ & $-1.37 \mathrm{E}-02$ & $-8.73 \mathrm{E}-03$ & $-9.59 \mathrm{E}+01$ & $7.30 \mathrm{E}-03$ & $8.40 \mathrm{E}-03$ \\
\hline b4 & 8.27E-04 & $5.75 \mathrm{E}-04$ & $3.74 \mathrm{E}-04$ & $7.07 \mathrm{E}+00$ & $2.12 \mathrm{E}-04$ & $-2.05 \mathrm{E}-04$ \\
\hline b5 & $6.10 \mathrm{E}-07$ & $9.27 \mathrm{E}-08$ & $2.83 \mathrm{E}-06$ & $3.59 \mathrm{E}-01$ & $1.12 \mathrm{E}-04$ & $2.54 \mathrm{E}-06$ \\
\hline
\end{tabular}

Table 7. Air-Kerma calculations by EGSnrc code, Calculation by Equation 4 and analytical fit in this work are identical with the comparison for those reports CEA-R-6235 and ICRU 57, in unit $\left(\mathbf{p G y} \cdot \mathrm{cm}^{2}\right)$.

\begin{tabular}{|c|c|c|c|c|c|c|}
\hline Energy $(\mathrm{MeV})$ & EGSnrc & Analytical fits in this work & ICRU 57 & CEA-R-6235 & Calculation by Eq. 5 & Relative differences\% \\
\hline 0.015 & $3.11 \pm 0.02$ & 3.12 & 3.11 & 3.11 & 3.2 & $0.00 \%$ \\
\hline 0.02 & $1.73 \pm 0.014$ & 1.70 & 1.73 & 1.73 & 1.73 & $0.00 \%$ \\
\hline 0.03 & $0.74 \pm 0.013$ & 0.78 & 0.74 & 0.74 & 0.74 & $0.00 \%$ \\
\hline 0.04 & $0.44 \pm 0.012$ & 0.46 & 0.44 & 0.44 & 0.44 & $0.00 \%$ \\
\hline 0.05 & $0.33 \pm 0.011$ & 0.33 & 0.33 & 0.33 & 0.33 & $0.00 \%$ \\
\hline 0.06 & $0.29 \pm 0.010$ & 0.28 & 0.29 & 0.29 & 0.29 & $0.00 \%$ \\
\hline 0.08 & $0.30 \pm 0.019$ & 0.28 & 0.31 & 0.31 & 0.31 & $0.00 \%$ \\
\hline 0.1 & $0.37 \pm 0.018$ & 0.34 & 0.37 & 0.37 & 0.37 & $0.00 \%$ \\
\hline 0.15 & $0.59 \pm 0.017$ & 0.58 & 0.6 & 0.6 & 0.6 & $1.67 \%$ \\
\hline 0.2 & $0.85 \pm 0.016$ & 0.86 & 0.86 & 0.85 & 0.86 & $1.16 \%$ \\
\hline 0.3 & $1.38 \pm 0.015$ & 1.42 & 1.38 & 1.38 & 1.38 & $0.00 \%$ \\
\hline 0.4 & $1.89 \pm 0.015$ & 1.94 & 1.89 & 1.89 & 1.89 & $0.00 \%$ \\
\hline 0.5 & $2.39 \pm 0.010$ & 2.42 & 2.38 & 2.38 & 2.38 & $0.42 \%$ \\
\hline 0.6 & $2.82 \pm 0.019$ & 2.83 & 2.84 & 2.84 & 2.84 & $0.70 \%$ \\
\hline 0.8 & $3.71 \pm 0.018$ & 3.73 & 3.7 & 3.7 & 3.7 & $0.27 \%$ \\
\hline 1 & $4.48 \pm 0.017$ & 4.42 & 4.47 & 4.47 & 4.48 & $0.22 \%$ \\
\hline 1.5 & $6.14 \pm 0.016$ & 6.17 & 6.13 & 6.14 & 6.14 & $0.16 \%$ \\
\hline 2 & $7.54 \pm 0.015$ & 7.48 & 7.54 & 7.55 & 7.55 & $0.00 \%$ \\
\hline 3 & $9.95 \pm 0.014$ & 9.88 & 9.95 & 9.95 & 9.96 & $0.00 \%$ \\
\hline 4 & $12.26 \pm 0.013$ & 12.08 & 12.1 & 12.11 & 12.12 & $1.32 \%$ \\
\hline 5 & $13.94 \pm 0.012$ & 14.17 & 14.1 & 14.14 & 14.16 & $1.13 \%$ \\
\hline 6 & $16.29 \pm 0.012$ & 16.20 & 16.1 & 16.13 & 16.16 & $1.18 \%$ \\
\hline 8 & $19.90 \pm 0.011$ & 20.15 & 20.1 & 20.08 & 20.11 & $1.00 \%$ \\
\hline 10 & $24.10 \pm 0.011$ & 24.03 & 24.1 & 24.05 & 24.1 & $0.00 \%$ \\
\hline
\end{tabular}


Table 8. Conversion coefficients from photon fluence to personal dose equivalent in $\left(\mathrm{pSv} \cdot \mathrm{cm}^{2}\right)$ for angles of incidence from $0^{\circ}$ to a $30^{\circ}$, in terms of absorbed dose.

\begin{tabular}{|c|c|c|c|c|c|c|}
\hline \multirow{2}{*}{$\begin{array}{l}\text { Energy } \\
(\mathrm{MeV})\end{array}$} & \multicolumn{2}{|c|}{$\mathbf{0}^{\circ}$} & \multicolumn{2}{|c|}{$15^{\circ}$} & \multicolumn{2}{|c|}{$30^{\circ}$} \\
\hline & EGSnrc & $\begin{array}{c}\text { Analytical fits } \\
\text { in this work }\end{array}$ & EGSnrc & $\begin{array}{l}\text { Analytical fits } \\
\text { in this work }\end{array}$ & EGSnrc & $\begin{array}{c}\text { Analytical fits } \\
\text { in this work }\end{array}$ \\
\hline 0.015 & $0.93 \pm 0.02$ & 0.93 & $0.92 \pm 0.03$ & 0.92 & $0.79 \pm 0.02$ & 0.68 \\
\hline 0.02 & $1.12 \pm 0.012$ & 1.11 & $1.08 \pm 0.04$ & 1.08 & $1.02 \pm 0.02$ & 0.97 \\
\hline 0.03 & $0.86 \pm 0.03$ & 0.86 & $0.830 \pm 0.017$ & 0.82 & $0.80 \pm 0.013$ & 0.78 \\
\hline 0.04 & $0.67 \pm 0.02$ & 0.68 & $0.66 \pm 0.009$ & 0.65 & $0.66 \pm 0.014$ & 0.63 \\
\hline 0.05 & $0.58 \pm 0.012$ & 0.59 & $0.580 \pm 0.01$ & 0.58 & $0.55 \pm 0.012$ & 0.55 \\
\hline 0.06 & $0.57 \pm 0.017$ & 0.56 & $0.530 \pm 0.021$ & 0.56 & $0.54 \pm 0.013$ & 0.53 \\
\hline 0.08 & $0.580 \pm 0.019$ & 0.58 & $0.600 \pm 0.012$ & 0.59 & $0.57 \pm 0.014$ & 0.57 \\
\hline 0.1 & $0.67 \pm 0.012$ & 0.66 & $0.680 \pm 0.014$ & 0.67 & $0.64 \pm 0.015$ & 0.65 \\
\hline 0.15 & $0.950 \pm 0.015$ & 0.94 & $0.940 \pm 0.017$ & 0.95 & $0.96 \pm 0.013$ & 0.94 \\
\hline 0.2 & $1.270 \pm 0.016$ & 1.26 & $1.25 \pm 0.012$ & 1.25 & $1.30 \pm 0.017$ & 1.26 \\
\hline 0.3 & $1.840 \pm 0.02$ & 1.89 & $1.860 \pm 0.017$ & 1.86 & $1.86 \pm 0.015$ & 1.88 \\
\hline 0.4 & $2.480 \pm 0.013$ & 2.48 & $2.520 \pm 0.015$ & 2.44 & $2.49 \pm 0.016$ & 2.46 \\
\hline 0.5 & $2.970 \pm 0.017$ & 3.03 & $2.99 \pm 0.012$ & 2.98 & $3.11 \pm 0.017$ & 3.00 \\
\hline 0.6 & $3.51 \pm 0.017$ & 3.54 & $3.370 \pm 0.017$ & 3.49 & $3.49 \pm 0.018$ & 3.50 \\
\hline 0.8 & $4.630 \pm 0.013$ & 4.46 & $4.400 \pm 0.014$ & 4.42 & $4.34 \pm 0.019$ & 4.40 \\
\hline 1 & $5.200 \pm 0.017$ & 5.29 & $5.340 \pm 0.014$ & 5.27 & $5.22 \pm 0.02$ & 5.22 \\
\hline 1.5 & $7.050 \pm 0.013$ & 7.06 & $7.120 \pm 0.015$ & 7.14 & $7.08 \pm 0.009$ & 7.01 \\
\hline 3 & $10.500 \pm 0.021$ & 10.50 & $10.400 \pm 0.016$ & 10.40 & $10.63 \pm 0.021$ & 10.62 \\
\hline 6 & $8.810 \pm 0.019$ & 8.81 & $9.030 \pm 0.018$ & 9.03 & $10.75 \pm 0.013$ & 10.76 \\
\hline 10 & $8.07 \pm 0.012$ & 8.07 & $8.48 \pm 0.012$ & 8.48 & $8.52 \pm 0.013$ & 8.52 \\
\hline
\end{tabular}

Table 9. Conversion coefficients from photon fluence to personal dose equivalent in $\left(\mathrm{pSv} \cdot \mathrm{cm}^{2}\right)$ for angles of incidence from $45^{\circ}$ to $75^{\circ}$, in terms of absorbed dose.

\begin{tabular}{|c|c|c|c|c|c|c|}
\hline \multirow[b]{2}{*}{ Energy (MeV) } & \multicolumn{2}{|c|}{$45^{\circ}$} & \multicolumn{2}{|c|}{$60^{\circ}$} & \multicolumn{2}{|c|}{$75^{\circ}$} \\
\hline & EGSnrc & $\begin{array}{l}\text { Analytical fits } \\
\text { in this work }\end{array}$ & EGSnrc & $\begin{array}{l}\text { Analytical fits } \\
\text { in this work }\end{array}$ & EGSnrc & $\begin{array}{l}\text { Analytical fits } \\
\text { in this work }\end{array}$ \\
\hline 0.015 & $0.56 \pm 0.009$ & 0.47 & $0.26 \pm 0.009$ & 0.26 & $0.04 \pm 0.02$ & 0.04 \\
\hline 0.02 & $0.86 \pm 0.009$ & 0.80 & $0.61 \pm 0.009$ & 0.54 & $0.21 \pm 0.01$ & 0.21 \\
\hline 0.03 & $0.75 \pm 0.02$ & 0.72 & $0.63 \pm 0.02$ & 0.61 & $0.36 \pm 0.02$ & 0.36 \\
\hline 0.04 & $0.59 \pm 0.02$ & 0.56 & $0.540 \pm 0.017$ & 0.49 & $0.35 \pm 0.015$ & 0.35 \\
\hline 0.05 & $0.54 \pm 0.013$ & 0.48 & $0.48 \pm 0.010$ & 0.43 & $0.32 \pm 0.019$ & 0.33 \\
\hline 0.06 & $0.49 \pm 0.014$ & 0.46 & $0.44 \pm 0.019$ & 0.43 & $0.34 \pm 0.019$ & 0.33 \\
\hline 0.08 & $0.54 \pm 0.013$ & 0.51 & $0.490 \pm 0.017$ & 0.49 & $0.360 \pm 0.017$ & 0.36 \\
\hline 0.1 & $0.65 \pm 0.012$ & 0.62 & $0.59 \pm 0.018$ & 0.58 & $0.45 \pm 0.018$ & 0.44 \\
\hline 0.15 & $0.92 \pm 0.014$ & 0.95 & $0.87 \pm 0.017$ & 0.86 & $0.67 \pm 0.017$ & 0.68 \\
\hline 0.2 & $1.25 \pm 0.011$ & 1.28 & $1.13 \pm 0.016$ & 1.16 & $0.95 \pm 0.017$ & 0.95 \\
\hline 0.3 & $1.86 \pm 0.013$ & 1.90 & $1.87 \pm 0.015$ & 1.75 & $1.48 \pm 0.017$ & 1.51 \\
\hline 0.4 & $2.51 \pm 0.014$ & 2.47 & $2.42 \pm 0.014$ & 2.32 & $2.04 \pm 0.017$ & 2.05 \\
\hline 0.5 & $2.91 \pm 0.012$ & 2.99 & $2.90 \pm 0.013$ & 2.86 & $2.67 \pm 0.018$ & 2.58 \\
\hline 0.6 & $3.39 \pm 0.014$ & 3.49 & $3.40 \pm 0.012$ & 3.39 & $3.06 \pm 0.019$ & 3.09 \\
\hline 0.8 & $4.44 \pm 0.015$ & 4.43 & $4.42 \pm 0.012$ & 4.44 & $4.06 \pm 0.017$ & 4.06 \\
\hline 1 & $4.99 \pm 0.016$ & 5.29 & $5.23 \pm 0.014$ & 5.20 & $4.83 \pm 0.015$ & 4.85 \\
\hline 1.5 & $7.24 \pm 0.017$ & 7.17 & $7.070 \pm 0.017$ & 7.13 & $6.81 \pm 0.014$ & 6.83 \\
\hline 3 & $10.50 \pm 0.009$ & 10.58 & $11.00 \pm 0.008$ & 10.99 & $10.99 \pm 0.013$ & 10.99 \\
\hline 6 & $12.40 \pm 0.012$ & 12.32 & $14.45 \pm 0.02$ & 14.44 & $15.62 \pm 0.008$ & 15.63 \\
\hline 10 & $12.20 \pm 0.018$ & 12.24 & $15.490 \pm 0.017$ & 15.49 & $19.52 \pm 0.010$ & 19.61 \\
\hline
\end{tabular}


Table 10. Conversion coefficient from photon fluence to personal dose equivalent in $\left(\mathrm{pSv} \cdot \mathrm{cm}^{2}\right)$ for angles of incidence from $0^{\circ}$ to a $15^{\circ}$, in terms of Kerma approximation and relative differences.

\begin{tabular}{|c|c|c|c|c|c|c|c|c|}
\hline \multirow{2}{*}{$\begin{array}{l}\text { Energy } \\
(\mathrm{MeV})\end{array}$} & \multicolumn{4}{|c|}{ 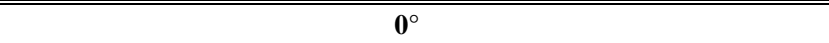 } & \multicolumn{4}{|c|}{$15^{\circ}$} \\
\hline & EGSnrc & $\begin{array}{l}\text { Analytical fits } \\
\text { in this work }\end{array}$ & ICRU 57 & $\begin{array}{c}\text { Relative differences } \\
\%\end{array}$ & EGSnrc & $\begin{array}{l}\text { Analytical fits } \\
\text { in this work }\end{array}$ & ICRU 57 & $\begin{array}{c}\text { Relative } \\
\text { differences\% }\end{array}$ \\
\hline 0.015 & $0.93 \pm 0.010$ & 0.82 & 0.82 & $11.52 \%$ & $0.91 \pm 0.013$ & 0.80 & 0.8 & $12.88 \%$ \\
\hline 0.02 & $1.12 \pm 0.011$ & 1.06 & 1.06 & $5.66 \%$ & $1.08 \pm 0.013$ & 1.04 & 1.04 & $3.52 \%$ \\
\hline 0.03 & $0.86 \pm 0.011$ & 0.82 & 0.82 & $3.85 \%$ & $0.83 \pm 0.012$ & 0.81 & 0.81 & $2.18 \%$ \\
\hline 0.04 & $0.66 \pm 0.012$ & 0.65 & 0.65 & $1.32 \%$ & $0.66 \pm 0.011$ & 0.64 & 0.64 & $1.85 \%$ \\
\hline 0.05 & $0.57 \pm 0.013$ & 0.57 & 0.58 & $0.54 \%$ & $0.58 \pm 0.012$ & 0.56 & 0.57 & $1.32 \%$ \\
\hline 0.06 & $0.56 \pm 0.014$ & 0.55 & 0.55 & $1.96 \%$ & $0.53 \pm 0.011$ & 0.54 & 0.54 & $2.77 \%$ \\
\hline 0.08 & $0.58 \pm 0.015$ & 0.59 & 0.58 & $0.00 \%$ & $0.59 \pm 0.012$ & 0.58 & 0.58 & $2.44 \%$ \\
\hline 0.1 & $0.66 \pm 0.016$ & 0.67 & 0.67 & $0.31 \%$ & $0.67 \pm 0.012$ & 0.67 & 0.66 & $1.34 \%$ \\
\hline 0.15 & $0.94 \pm 0.017$ & 0.96 & 0.95 & $1.26 \%$ & $0.93 \pm 0.013$ & 0.95 & 0.95 & $1.54 \%$ \\
\hline 0.2 & $1.26 \pm 0.017$ & 1.27 & 1.27 & $0.70 \%$ & $1.24 \pm 0.013$ & 1.27 & 1.27 & $1.86 \%$ \\
\hline 0.3 & $1.83 \pm 0.018$ & 1.88 & 1.89 & $3.16 \%$ & $1.86 \pm 0.014$ & 1.88 & 1.89 & $1.67 \%$ \\
\hline 0.4 & $2.45 \pm 0.019$ & 2.46 & 2.46 & $0.23 \%$ & $2.51 \pm 0.014$ & 2.46 & 2.47 & $1.86 \%$ \\
\hline 0.5 & $3.00 \pm 0.010$ & 2.99 & 3 & $0.13 \%$ & $2.99 \pm 0.015$ & 3.00 & 3.02 & $0.99 \%$ \\
\hline 0.6 & $3.49 \pm 0.011$ & 3.49 & 3.46 & $0.88 \%$ & $3.38 \pm 0.015$ & 3.50 & 3.47 & $2.91 \%$ \\
\hline 0.8 & $4.54 \pm 0.012$ & 4.40 & 4.41 & $2.75 \%$ & $4.23 \pm 0.016$ & 4.41 & 4.42 & $4.39 \%$ \\
\hline 1 & $5.33 \pm 0.012$ & 5.22 & 5.23 & $1.82 \%$ & $5.33 \pm 0.012$ & 5.23 & 5.23 & $1.94 \%$ \\
\hline 1.5 & $7.05 \pm 0.013$ & 6.99 & 6.99 & $0.80 \%$ & $6.74 \pm 0.012$ & 7.00 & 7.01 & $3.90 \%$ \\
\hline 3 & $11.10 \pm 0.013$ & 11.09 & 11.11 & $0.13 \%$ & $11.47 \pm 0.010$ & 11.46 & 11.17 & $2.63 \%$ \\
\hline 6 & $17.74 \pm 0.013$ & 18.08 & 18.08 & $1.93 \%$ & $17.99 \pm 0.011$ & 18.14 & 18.13 & $0.77 \%$ \\
\hline 10 & $26.60 \pm 0.014$ & 26.66 & 26.66 & $0.24 \%$ & $25.55 \pm 0.012$ & 26.62 & 26.61 & $4.16 \%$ \\
\hline
\end{tabular}

Table 11. Conversion coefficient from photon fluence to personal dose equivalent in $\left(\mathrm{pSv}^{\circ} \mathrm{cm}^{2}\right)$ for angles of incidence from $30^{\circ}$ to a $45^{\circ}$, in terms of Kerma approximation and relative differences.

\begin{tabular}{|c|c|c|c|c|c|c|c|c|}
\hline \multirow{2}{*}{$\begin{array}{l}\text { Energy } \\
(\mathrm{MeV})\end{array}$} & \multicolumn{4}{|c|}{$3 \mathbf{3 0}^{\circ}$} & \multicolumn{4}{|c|}{$44^{\circ}$} \\
\hline & EGSnrc & $\begin{array}{l}\text { Analytical fits } \\
\text { in this work }\end{array}$ & ICRU 57 & $\begin{array}{c}\text { Relative } \\
\text { differences \% }\end{array}$ & EGSnrc & $\begin{array}{l}\text { Analytical fits } \\
\text { in this work }\end{array}$ & $\begin{array}{c}\text { ICRU } \\
57\end{array}$ & $\begin{array}{c}\text { Relative } \\
\text { differences \% }\end{array}$ \\
\hline 0.015 & $0.79 \pm 0.013$ & 0.68 & 0.68 & $13.96 \%$ & $0.57 \pm 0.009$ & 0.47 & 0.47 & $16.08 \%$ \\
\hline 0.02 & $1.01 \pm 0.013$ & 0.97 & 0.97 & $4.87 \%$ & $0.86 \pm 0.009$ & 0.81 & 0.81 & $6.01 \%$ \\
\hline 0.03 & $0.80 \pm 0.013$ & 0.78 & 0.78 & $1.86 \%$ & $0.74 \pm 0.02$ & 0.70 & 0.71 & $3.96 \%$ \\
\hline 0.04 & $0.66 \pm 0.013$ & 0.63 & 0.63 & $4.64 \%$ & $0.59 \pm 0.02$ & 0.58 & 0.58 & $1.09 \%$ \\
\hline 0.05 & $0.54 \pm 0.013$ & 0.56 & 0.56 & $2.51 \%$ & $0.53 \pm 0.013$ & 0.52 & 0.51 & $3.34 \%$ \\
\hline 0.06 & $0.54 \pm 0.014$ & 0.53 & 0.53 & $0.80 \%$ & $0.48 \pm 0.014$ & 0.50 & 0.5 & $3.65 \%$ \\
\hline 0.08 & $0.57 \pm 0.014$ & 0.56 & 0.56 & $1.31 \%$ & $0.54 \pm 0.013$ & 0.53 & 0.53 & $1.11 \%$ \\
\hline 0.1 & $0.63 \pm 0.013$ & 0.65 & 0.65 & $2.62 \%$ & $0.64 \pm 0.012$ & 0.61 & 0.62 & $3.68 \%$ \\
\hline 0.15 & $0.95 \pm 0.013$ & 0.94 & 0.94 & $1.78 \%$ & $0.92 \pm 0.014$ & 0.90 & 0.9 & $1.95 \%$ \\
\hline 0.2 & $1.28 \pm 0.012$ & 1.26 & 1.26 & $1.92 \%$ & $1.24 \pm 0.011$ & 1.22 & 1.22 & $2.06 \%$ \\
\hline 0.3 & $1.84 \pm 0.011$ & 1.88 & 1.88 & $2.34 \%$ & $1.86 \pm 0.013$ & 1.85 & 1.86 & $0.31 \%$ \\
\hline 0.4 & $2.47 \pm 0.011$ & 2.46 & 2.46 & $0.23 \%$ & $2.48 \pm 0.014$ & 2.45 & 2.44 & $1.78 \%$ \\
\hline 0.5 & $3.08 \pm 0.011$ & 3.00 & 3.01 & $2.20 \%$ & $2.96 \pm 0.012$ & 3.00 & 3 & $1.60 \%$ \\
\hline 0.6 & $3.55 \pm 0.012$ & 3.49 & 3.47 & $2.15 \%$ & $3.42 \pm 0.014$ & 3.51 & 3.47 & $1.47 \%$ \\
\hline 0.8 & $4.37 \pm 0.013$ & 4.41 & 4.43 & $1.31 \%$ & $4.43 \pm 0.015$ & 4.43 & 4.45 & $0.27 \%$ \\
\hline 1 & $5.35 \pm 0.014$ & 5.23 & 5.21 & $2.65 \%$ & $5.01 \pm 0.016$ & 5.26 & 5.28 & $5.20 \%$ \\
\hline 1.5 & $7.24 \pm 0.015$ & 7.00 & 7.01 & $3.17 \%$ & $6.85 \pm 0.017$ & 7.04 & 7.04 & $2.71 \%$ \\
\hline 3 & $10.62 \pm 0.016$ & 11.23 & 11.23 & $5.72 \%$ & $11.00 \pm 0.009$ & 11.09 & 11.09 & $0.84 \%$ \\
\hline 6 & $17.15 \pm 0.019$ & 18.13 & 18.13 & $5.75 \%$ & $17.20 \pm 0.012$ & 17.94 & 17.93 & $4.26 \%$ \\
\hline 10 & $25.44 \pm 0.010$ & 26.53 & 26.53 & $4.30 \%$ & $25.70 \pm 0.018$ & 26.37 & 26.37 & $2.61 \%$ \\
\hline
\end{tabular}


Table 12. Conversion coefficient from photon fluence to personal dose equivalent in $\left(\mathrm{pSv} \cdot \mathrm{cm}^{2}\right)$ for angles of incidence from $60^{\circ}$ to a $75^{\circ}$, in terms of Kerma approximation and relative differences.

\begin{tabular}{|c|c|c|c|c|c|c|c|c|}
\hline \multirow{2}{*}{$\begin{array}{c}\text { Energy } \\
(\mathrm{MeV})\end{array}$} & \multicolumn{4}{|c|}{$60^{\circ}$} & \multicolumn{4}{|c|}{$75^{\circ}$} \\
\hline & EGSnrc & $\begin{array}{l}\text { Analytical fits } \\
\text { in this work }\end{array}$ & ICRU 57 & $\begin{array}{c}\text { Relative } \\
\text { differences \% }\end{array}$ & EGSnrc & $\begin{array}{l}\text { Analytical fits } \\
\text { in this work }\end{array}$ & $\begin{array}{c}\text { ICRU } \\
\mathbf{5 7} \\
\end{array}$ & $\begin{array}{c}\text { Relative } \\
\text { differences \% }\end{array}$ \\
\hline 0.015 & $0.26 \pm 0.009$ & 0.26 & 0.21 & $16.92 \%$ & $0.04 \pm 0.02$ & 0.02 & 0.02 & $29.57 \%$ \\
\hline 0.02 & $0.61 \pm 0.010$ & 0.55 & 0.55 & $9.73 \%$ & $0.21 \pm 0.010$ & 0.19 & 0.18 & $16.63 \%$ \\
\hline 0.03 & $0.62 \pm 0.02$ & 0.59 & 0.59 & $5.51 \%$ & $0.36 \pm 0.02$ & 0.33 & 0.34 & $4.90 \%$ \\
\hline 0.04 & $0.53 \pm 0.017$ & 0.50 & 0.5 & $6.75 \%$ & $0.35 \pm 0.015$ & 0.33 & 0.32 & $6.98 \%$ \\
\hline 0.05 & $0.45 \pm 0.010$ & 0.45 & 0.45 & $0.74 \%$ & $0.32 \pm 0.019$ & 0.31 & 0.3 & $5.20 \%$ \\
\hline 0.06 & $0.43 \pm 0.019$ & 0.44 & 0.44 & $1.04 \%$ & $0.33 \pm 0.019$ & 0.30 & 0.31 & $7.40 \%$ \\
\hline 0.08 & $0.49 \pm 0.017$ & 0.47 & 0.47 & $4.31 \%$ & $0.35 \pm 0.017$ & 0.34 & 0.34 & $2.94 \%$ \\
\hline 0.1 & $0.58 \pm 0.018$ & 0.56 & 0.56 & $4.35 \%$ & $0.42 \pm 0.018$ & 0.41 & 0.41 & $3.62 \%$ \\
\hline 0.15 & $0.87 \pm 0.017$ & 0.83 & 0.83 & $4.21 \%$ & $0.68 \pm 0.017$ & 0.65 & 0.64 & $4.66 \%$ \\
\hline 0.2 & $1.13 \pm 0.016$ & 1.14 & 1.14 & $1.52 \%$ & $0.95 \pm 0.017$ & 0.92 & 0.92 & $3.30 \%$ \\
\hline 0.3 & $1.85 \pm 0.015$ & 1.76 & 1.76 & $5.10 \%$ & $1.48 \pm 0.017$ & 1.47 & 1.46 & $1.65 \%$ \\
\hline 0.4 & $2.41 \pm 0.014$ & 2.34 & 2.35 & $2.71 \%$ & $2.05 \pm 0.017$ & 2.00 & 2 & $2.29 \%$ \\
\hline 0.5 & $2.88 \pm 0.013$ & 2.89 & 2.91 & $0.74 \%$ & $2.64 \pm 0.018$ & 2.52 & 2.54 & $3.66 \%$ \\
\hline 0.6 & $3.40 \pm 0.012$ & 3.41 & 3.37 & $0.72 \%$ & $3.05 \pm 0.019$ & 3.02 & 3 & $1.47 \%$ \\
\hline 0.8 & $4.45 \pm 0.012$ & 4.34 & 4.36 & $2.15 \%$ & $4.10 \pm 0.017$ & 3.93 & 3.94 & $3.97 \%$ \\
\hline 1 & $5.23 \pm 0.014$ & 5.18 & 5.18 & $1.03 \%$ & $4.87 \pm 0.015$ & 4.76 & 4.76 & $2.39 \%$ \\
\hline 1.5 & $6.91 \pm 0.017$ & 6.97 & 6.97 & $0.89 \%$ & $6.90 \pm 0.014$ & 6.53 & 6.53 & $5.38 \%$ \\
\hline 3 & $11.01 \pm 0.008$ & 11.09 & 11.09 & $0.77 \%$ & $10.46 \pm 0.013$ & 10.65 & 10.65 & $1.78 \%$ \\
\hline 6 & $17.54 \pm 0.02$ & 18.02 & 18.02 & $2.75 \%$ & $17.33 \pm 0.008$ & 17.99 & 17.99 & $3.77 \%$ \\
\hline 10 & $26.16 \pm 0.017$ & 26.45 & 26.45 & $1.13 \%$ & $24.89 \pm 0.010$ & 25.77 & 25.76 & $3.48 \%$ \\
\hline
\end{tabular}

Table 13. Conversion coefficients from photon air Kerma to personal dose equivalent in (Sv/Gy) for angles of incidence from $0^{\circ}$ to a $30^{\circ}$, in terms of absorbed dose.

\begin{tabular}{|c|c|c|c|c|c|c|}
\hline \multirow[b]{2}{*}{ Energy (MeV) } & \multicolumn{2}{|c|}{$\mathbf{0}^{\circ}$} & \multicolumn{2}{|c|}{$15^{\circ}$} & \multicolumn{2}{|c|}{$30^{\circ}$} \\
\hline & EGSnrc & $\begin{array}{l}\text { Analytical fits } \\
\text { in this work }\end{array}$ & EGSnrc & $\begin{array}{l}\text { Analytical fits } \\
\text { n this work }\end{array}$ & EGSnrc & $\begin{array}{l}\text { Analytical fits } \\
\text { in this work }\end{array}$ \\
\hline 0.015 & $0.30 \pm 0.02$ & 0.28 & $0.29 \pm 0.03$ & 0.28 & $0.25 \pm 0.02$ & 0.27 \\
\hline 0.02 & $0.65 \pm 0.012$ & 0.58 & $0.62 \pm 0.012$ & 0.57 & $0.59 \pm 0.02$ & 0.55 \\
\hline 0.03 & $1.16 \pm 0.03$ & 1.11 & $1.12 \pm 0.017$ & 1.09 & $1.08 \pm 0.013$ & 1.10 \\
\hline 0.04 & $1.52 \pm 0.02$ & 1.52 & $1.51 \pm 0.009$ & 1.49 & $1.50 \pm 0.014$ & 1.49 \\
\hline 0.05 & $1.78 \pm 0.012$ & 1.76 & $1.78 \pm 0.010$ & 1.74 & $1.68 \pm 0.012$ & 1.72 \\
\hline 0.06 & $1.95 \pm 0.017$ & 1.87 & $1.84 \pm 0.021$ & 1.86 & $1.86 \pm 0.013$ & 1.82 \\
\hline 0.08 & $1.92 \pm 0.019$ & 1.89 & $1.96 \pm 0.012$ & 1.89 & $1.88 \pm 0.014$ & 1.84 \\
\hline 0.1 & $1.82 \pm 0.012$ & 1.82 & $1.84 \pm 0.014$ & 1.81 & $1.73 \pm 0.015$ & 1.78 \\
\hline 0.15 & $1.60 \pm 0.015$ & 1.63 & $1.59 \pm 0.017$ & 1.62 & $1.62 \pm 0.013$ & 1.62 \\
\hline 0.2 & $1.48 \pm 0.016$ & 1.50 & $1.46 \pm 0.012$ & 1.49 & $1.52 \pm 0.017$ & 1.51 \\
\hline 0.3 & $1.33 \pm 0.02$ & 1.36 & $1.35 \pm 0.017$ & 1.36 & $1.35 \pm 0.015$ & 1.38 \\
\hline 0.4 & $1.31 \pm 0.013$ & 1.29 & $1.33 \pm 0.015$ & 1.29 & $1.32 \pm 0.016$ & 1.31 \\
\hline 0.5 & $1.24 \pm 0.017$ & 1.25 & $1.25 \pm 0.012$ & 1.25 & $1.30 \pm 0.017$ & 1.27 \\
\hline 0.6 & $1.24 \pm 0.017$ & 1.22 & $1.20 \pm 0.017$ & 1.22 & $1.24 \pm 0.018$ & 1.24 \\
\hline 0.8 & $1.25 \pm 0.013$ & 1.19 & $1.19 \pm 0.014$ & 1.19 & $1.17 \pm 0.019$ & 1.19 \\
\hline 1 & $1.16 \pm 0.017$ & 1.18 & $1.19 \pm 0.014$ & 1.17 & $1.17 \pm 0.012$ & 1.17 \\
\hline 1.5 & $1.15 \pm 0.013$ & 1.16 & $1.16 \pm 0.015$ & 1.15 & $1.15 \pm 0.009$ & 1.15 \\
\hline 3 & $1.06 \pm 0.021$ & 1.12 & $1.05 \pm 0.016$ & 1.11 & $1.07 \pm 0.021$ & 1.10 \\
\hline 6 & $0.54 \pm 0.019$ & 0.56 & $0.55 \pm 0.018$ & 0.55 & $0.66 \pm 0.013$ & 0.66 \\
\hline 10 & $0.33 \pm 0.012$ & 0.35 & $0.35 \pm 0.012$ & 0.35 & $0.35 \pm 0.013$ & 0.35 \\
\hline
\end{tabular}


Table 14. Conversion coefficients from photon air Kerma to personal dose equivalent in (Sv/Gy) for angles of incidence from $45^{\circ}$ to a $75^{\circ}$, in terms of absorbed dose.

\begin{tabular}{|c|c|c|c|c|c|c|}
\hline \multirow[b]{2}{*}{ Energy (MeV) } & \multicolumn{2}{|c|}{$45^{\circ}$} & \multicolumn{2}{|c|}{$60^{\circ}$} & \multicolumn{2}{|c|}{$75^{\circ}$} \\
\hline & EGSnrc & $\begin{array}{l}\text { Analytical fits } \\
\text { in this work }\end{array}$ & EGSnrc & $\begin{array}{l}\text { Analytical fits } \\
\text { in this work }\end{array}$ & EGSnrc & $\begin{array}{l}\text { Analytical fits } \\
\text { in this work }\end{array}$ \\
\hline 0.015 & $0.18 \pm 0.01$ & 0.20 & $0.08 \pm 0.01$ & 0.07 & $0.01 \pm 0.01$ & 0.00 \\
\hline 0.02 & $0.50 \pm 0.01$ & 0.48 & $0.35 \pm 0.01$ & 0.36 & $0.12 \pm 0.01$ & 0.14 \\
\hline 0.03 & $1.01 \pm 0.01$ & 1.01 & $0.85 \pm 0.01$ & 0.85 & $0.48 \pm 0.01$ & 0.46 \\
\hline 0.04 & $1.35 \pm 0.01$ & 1.38 & $1.22 \pm 0.01$ & 1.20 & $0.79 \pm 0.01$ & 0.79 \\
\hline 0.05 & $1.65 \pm 0.01$ & 1.61 & $1.40 \pm 0.01$ & 1.41 & $0.99 \pm 0.01$ & 1.02 \\
\hline 0.06 & $1.68 \pm 0.01$ & 1.72 & $1.50 \pm 0.01$ & 1.53 & $1.16 \pm 0.01$ & 1.13 \\
\hline 0.08 & $1.78 \pm 0.01$ & 1.77 & $1.62 \pm 0.01$ & 1.60 & $1.18 \pm 0.01$ & 1.18 \\
\hline 0.1 & $1.76 \pm 0.01$ & 1.73 & $1.59 \pm 0.01$ & 1.58 & $1.13 \pm 0.01$ & 1.16 \\
\hline 0.15 & $1.56 \pm 0.01$ & 1.59 & $1.46 \pm 0.01$ & 1.46 & $1.14 \pm 0.01$ & 1.12 \\
\hline 0.2 & $1.47 \pm 0.01$ & 1.49 & $1.32 \pm 0.01$ & 1.38 & $1.12 \pm 0.01$ & 1.10 \\
\hline 0.3 & $1.35 \pm 0.01$ & 1.36 & $1.35 \pm 0.01$ & 1.30 & $1.07 \pm 0.01$ & 1.09 \\
\hline 0.4 & $1.33 \pm 0.01$ & 1.29 & $1.28 \pm 0.01$ & 1.26 & $1.08 \pm 0.01$ & 1.09 \\
\hline 0.5 & $1.22 \pm 0.01$ & 1.24 & $1.21 \pm 0.01$ & 1.23 & $1.12 \pm 0.01$ & 1.09 \\
\hline 0.6 & $1.20 \pm 0.01$ & 1.21 & $1.21 \pm 0.01$ & 1.21 & $1.08 \pm 0.01$ & 1.09 \\
\hline 0.8 & $1.20 \pm 0.01$ & 1.16 & $1.19 \pm 0.01$ & 1.19 & $1.09 \pm 0.01$ & 1.09 \\
\hline 1 & $1.11 \pm 0.01$ & 1.12 & $1.17 \pm 0.01$ & 1.18 & $1.08 \pm 0.01$ & 1.09 \\
\hline 1.5 & $1.18 \pm 0.01$ & 1.18 & $1.15 \pm 0.01$ & 1.14 & $1.11 \pm 0.01$ & 1.10 \\
\hline 3 & $1.06 \pm 0.01$ & 1.07 & $1.11 \pm 0.01$ & 1.10 & $1.10 \pm 0.01$ & 1.10 \\
\hline 6 & $0.76 \pm 0.01$ & 0.76 & $0.89 \pm 0.01$ & 0.89 & $0.96 \pm 0.01$ & 0.96 \\
\hline 10 & $0.51 \pm 0.01$ & 0.51 & $0.64 \pm 0.01$ & 0.64 & $0.81 \pm 0.01$ & 0.81 \\
\hline
\end{tabular}

Table 15. Conversion coefficient from photon air Kerma to personal dose equivalent in $(\mathrm{Sv} / \mathrm{Gy})$, for angles of incidence from $0^{\circ}$ to a $15^{\circ}$, in terms of Kerma-approximation and relative differences.

\begin{tabular}{|c|c|c|c|c|c|c|c|c|}
\hline \multirow{2}{*}{$\begin{array}{l}\text { Energy } \\
(\mathrm{MeV})\end{array}$} & \multicolumn{4}{|c|}{$\overline{\mathbf{0}^{\circ}}$} & \multicolumn{4}{|c|}{$15^{\circ}$} \\
\hline & EGSnrc & $\begin{array}{c}\text { Analytical fits } \\
\text { in this work }\end{array}$ & ICRU 57 & $\begin{array}{c}\text { Relative } \\
\text { differences \% }\end{array}$ & EGSnrc & $\begin{array}{l}\text { Analytical fits } \\
\text { in this work }\end{array}$ & ICRU 57 & $\begin{array}{c}\text { Relative } \\
\text { differences \% }\end{array}$ \\
\hline 0.015 & $0.30 \pm 0.010$ & 0.26 & 0.26 & $11.52 \%$ & $0.29 \pm 0.013$ & 0.26 & 0.26 & $12.88 \%$ \\
\hline 0.02 & $0.65 \pm 0.011$ & 0.61 & 0.61 & $5.66 \%$ & $0.62 \pm 0.013$ & 0.60 & 0.6 & $3.52 \%$ \\
\hline 0.03 & $1.16 \pm 0.011$ & 1.11 & 1.11 & $3.85 \%$ & $1.12 \pm 0.012$ & 1.09 & 1.09 & $2.18 \%$ \\
\hline 0.04 & $1.51 \pm 0.012$ & 1.50 & 1.49 & $1.32 \%$ & $1.50 \pm 0.011$ & 1.47 & 1.47 & $1.85 \%$ \\
\hline 0.05 & $1.76 \pm 0.013$ & 1.76 & 1.77 & $0.54 \%$ & $1.77 \pm 0.012$ & 1.74 & 1.74 & $1.32 \%$ \\
\hline 0.06 & $1.93 \pm 0.014$ & 1.89 & 1.89 & $1.96 \%$ & $1.82 \pm 0.011$ & 1.88 & 1.87 & $2.77 \%$ \\
\hline 0.08 & $1.90 \pm 0.015$ & 1.90 & 1.9 & $0.00 \%$ & $1.94 \pm 0.012$ & 1.90 & 1.9 & $2.44 \%$ \\
\hline 0.1 & $1.81 \pm 0.016$ & 1.81 & 1.81 & $0.31 \%$ & $1.82 \pm 0.012$ & 1.80 & 1.8 & $1.34 \%$ \\
\hline 0.15 & $1.59 \pm 0.017$ & 1.61 & 1.61 & $1.26 \%$ & $1.58 \pm 0.013$ & 1.60 & 1.6 & $1.54 \%$ \\
\hline 0.2 & $1.48 \pm 0.017$ & 1.49 & 1.49 & $0.70 \%$ & $1.46 \pm 0.013$ & 1.49 & 1.49 & $1.86 \%$ \\
\hline 0.3 & $1.33 \pm 0.018$ & 1.37 & 1.37 & $3.16 \%$ & $1.35 \pm 0.014$ & 1.37 & 1.37 & $1.67 \%$ \\
\hline 0.4 & $1.30 \pm 0.019$ & 1.30 & 1.3 & $0.23 \%$ & $1.33 \pm 0.014$ & 1.31 & 1.31 & $1.86 \%$ \\
\hline 0.5 & $1.25 \pm 0.010$ & 1.26 & 1.26 & $0.13 \%$ & $1.25 \pm 0.015$ & 1.26 & 1.26 & $0.99 \%$ \\
\hline 0.6 & $1.24 \pm 0.011$ & 1.23 & 1.23 & $0.88 \%$ & $1.20 \pm 0.015$ & 1.23 & 1.23 & $2.91 \%$ \\
\hline 0.8 & $1.22 \pm 0.012$ & 1.19 & 1.19 & $2.75 \%$ & $1.14 \pm 0.016$ & 1.19 & 1.19 & $4.39 \%$ \\
\hline 1 & $1.19 \pm 0.012$ & 1.17 & 1.17 & $1.82 \%$ & $1.19 \pm 0.012$ & 1.17 & 1.17 & $1.94 \%$ \\
\hline 1.5 & $1.15 \pm 0.013$ & 1.14 & 1.14 & $0.80 \%$ & $1.10 \pm 0.012$ & 1.14 & 1.14 & $3.90 \%$ \\
\hline 3 & $1.12 \pm 0.013$ & 1.12 & 1.12 & $0.13 \%$ & $1.15 \pm 0.010$ & 1.12 & 1.12 & $2.63 \%$ \\
\hline 6 & $1.09 \pm 0.013$ & 1.11 & 1.11 & $1.93 \%$ & $1.10 \pm 0.011$ & 1.11 & 1.11 & $0.77 \%$ \\
\hline 10 & $1.11 \pm 0.014$ & 1.11 & 1.11 & $0.24 \%$ & $1.06 \pm 0.012$ & 1.11 & 1.11 & $4.16 \%$ \\
\hline
\end{tabular}


Table 16. Conversion coefficient from photon air Kerma to personal dose equivalent in (Sv/Gy), for angles of incidence from $30^{\circ}$ to a $45^{\circ}$, in terms of Kerma-approximation and relative differences.

\begin{tabular}{|c|c|c|c|c|c|c|c|c|}
\hline \multirow{2}{*}{$\begin{array}{l}\text { Energy } \\
(\mathrm{MeV})\end{array}$} & \multicolumn{4}{|c|}{$30^{\circ}$} & \multicolumn{4}{|c|}{$45^{\circ}$} \\
\hline & EGSnrc & $\begin{array}{c}\text { Analytical fits } \\
\text { in this work }\end{array}$ & ICRU 57 & $\begin{array}{c}\text { Relative } \\
\text { differences \% }\end{array}$ & EGSnrc & $\begin{array}{c}\text { Analytical } \\
\text { fits in this work }\end{array}$ & ICRU 57 & $\begin{array}{c}\text { Relative } \\
\text { differences \% }\end{array}$ \\
\hline 0.015 & $0.25 \pm 0.013$ & 0.22 & 0.22 & $13.96 \%$ & $0.18 \pm 0.00$ & 0.15 & 0.15 & $16.08 \%$ \\
\hline 0.02 & $0.59 \pm 0.013$ & 0.56 & 0.56 & $4.87 \%$ & $0.50 \pm 0.009$ & 0.47 & 0.47 & $6.01 \%$ \\
\hline 0.03 & $1.08 \pm 0.013$ & 1.06 & 1.06 & $1.86 \%$ & $1.01 \pm 0.02$ & 0.97 & 0.97 & $3.96 \%$ \\
\hline 0.04 & $1.50 \pm 0.013$ & 1.43 & 1.43 & $4.64 \%$ & $1.35 \pm 0.02$ & 1.33 & 1.33 & $1.09 \%$ \\
\hline 0.05 & $1.66 \pm 0.013$ & 1.69 & 1.7 & $2.51 \%$ & $1.63 \pm 0.013$ & 1.58 & 1.57 & $3.34 \%$ \\
\hline 0.06 & $1.85 \pm 0.014$ & 1.83 & 1.83 & $0.80 \%$ & $1.66 \pm 0.014$ & 1.71 & 1.72 & $3.65 \%$ \\
\hline 0.08 & $1.87 \pm 0.014$ & 1.85 & 1.85 & $1.31 \%$ & $1.77 \pm 0.013$ & 1.75 & 1.75 & $1.11 \%$ \\
\hline 0.1 & $1.72 \pm 0.013$ & 1.76 & 1.76 & $2.62 \%$ & $1.74 \pm 0.012$ & 1.68 & 1.68 & $3.68 \%$ \\
\hline 0.15 & $1.61 \pm 0.013$ & 1.58 & 1.58 & $1.78 \%$ & $1.55 \pm 0.014$ & 1.52 & 1.52 & $1.95 \%$ \\
\hline 0.2 & $1.51 \pm 0.012$ & 1.48 & 1.48 & $1.92 \%$ & $1.46 \pm 0.011$ & 1.43 & 1.43 & $2.06 \%$ \\
\hline 0.3 & $1.33 \pm 0.011$ & 1.36 & 1.36 & $2.34 \%$ & $1.35 \pm 0.013$ & 1.34 & 1.35 & $0.31 \%$ \\
\hline 0.4 & $1.30 \pm 0.011$ & 1.30 & 1.3 & $0.23 \%$ & $1.31 \pm 0.014$ & 1.29 & 1.29 & $1.78 \%$ \\
\hline 0.5 & $1.29 \pm 0.011$ & 1.26 & 1.26 & $2.20 \%$ & $1.24 \pm 0.014$ & 1.26 & 1.26 & $1.60 \%$ \\
\hline 0.6 & $1.26 \pm 0.012$ & 1.23 & 1.23 & $2.15 \%$ & $1.21 \pm 0.012$ & 1.23 & 1.23 & $1.47 \%$ \\
\hline 0.8 & $1.18 \pm 0.013$ & 1.19 & 1.19 & $1.31 \%$ & $1.20 \pm 0.015$ & 1.20 & 1.2 & $0.27 \%$ \\
\hline 1 & $1.19 \pm 0.014$ & 1.17 & 1.16 & $2.65 \%$ & $1.12 \pm 0.016$ & 1.18 & 1.18 & $5.20 \%$ \\
\hline 1.5 & $1.18 \pm 0.015$ & 1.14 & 1.14 & $3.17 \%$ & $1.12 \pm 0.017$ & 1.15 & 1.15 & $2.71 \%$ \\
\hline 3 & $1.07 \pm 0.016$ & 1.12 & 1.13 & $5.72 \%$ & $1.11 \pm 0.009$ & 1.11 & 1.11 & $0.84 \%$ \\
\hline 6 & $1.05 \pm 0.019$ & 1.11 & 1.11 & $5.75 \%$ & $1.06 \pm 0.012$ & 1.10 & 1.1 & $4.26 \%$ \\
\hline 10 & $1.06 \pm 0.010$ & 1.11 & 1.11 & $4.30 \%$ & $1.07 \pm 0.018$ & 1.10 & 1.1 & $2.61 \%$ \\
\hline
\end{tabular}

Table 17. Conversion coefficient from photon air Kerma to personal dose equivalent in (Sv/Gy), for angles of incidence from $60^{\circ}$ to a $75^{\circ}$, in terms of Kerma-approximation and relative differences.

\begin{tabular}{|c|c|c|c|c|c|c|c|c|}
\hline \multirow{2}{*}{$\begin{array}{l}\text { Energy } \\
(\mathrm{MeV})\end{array}$} & \multicolumn{4}{|c|}{$60^{\circ}$} & \multicolumn{4}{|c|}{$75^{\circ}$} \\
\hline & EGSnrc & $\begin{array}{c}\text { Analytical fits in } \\
\text { this work }\end{array}$ & ICRU 57 & $\begin{array}{c}\text { Relative } \\
\text { differences \% }\end{array}$ & EGSnrc & $\begin{array}{l}\text { Analytical fits } \\
\text { in this work }\end{array}$ & ICRU 57 & $\begin{array}{c}\text { Relative } \\
\text { differences \% }\end{array}$ \\
\hline 0.015 & $0.08 \pm 0.009$ & 0.07 & 0.07 & $16.92 \%$ & $0.01 \pm 0.02$ & 0.01 & 0.008 & $29.57 \%$ \\
\hline 0.02 & $0.35 \pm 0.010$ & 0.33 & 0.32 & $9.73 \%$ & $0.12 \pm 0.010$ & 0.10 & 0.102 & $16.63 \%$ \\
\hline 0.03 & $0.84 \pm 0.02$ & 0.79 & 0.8 & $5.51 \%$ & $0.48 \pm 0.02$ & 0.46 & 0.457 & $4.90 \%$ \\
\hline 0.04 & $1.21 \pm 0.017$ & 1.14 & 1.13 & $6.75 \%$ & $0.79 \pm 0.015$ & 0.74 & 0.736 & $6.98 \%$ \\
\hline 0.05 & $1.39 \pm 0.010$ & 1.38 & 1.38 & $0.74 \%$ & $0.98 \pm 0.019$ & 0.92 & 0.929 & $5.20 \%$ \\
\hline 0.06 & $1.48 \pm 0.019$ & 1.50 & 1.5 & $1.04 \%$ & $1.11 \pm 0.019$ & 1.05 & 1.061 & $4.53 \%$ \\
\hline 0.08 & $1.61 \pm 0.017$ & 1.55 & 1.54 & $4.31 \%$ & $1.16 \pm 0.017$ & 1.12 & 1.130 & $2.94 \%$ \\
\hline 0.1 & $1.58 \pm 0.018$ & 1.51 & 1.51 & $4.35 \%$ & $1.15 \pm 0.018$ & 1.11 & 1.108 & $3.62 \%$ \\
\hline 0.15 & $1.46 \pm 0.017$ & 1.40 & 1.4 & $4.21 \%$ & $1.14 \pm 0.017$ & 1.09 & 1.088 & $4.66 \%$ \\
\hline 0.2 & $1.32 \pm 0.016$ & 1.34 & 1.34 & $1.52 \%$ & $1.12 \pm 0.017$ & 1.07 & 1.080 & $3.30 \%$ \\
\hline 0.3 & $1.34 \pm 0.015$ & 1.27 & 1.27 & $5.10 \%$ & $1.07 \pm 0.017$ & 1.06 & 1.055 & $1.65 \%$ \\
\hline 0.4 & $1.28 \pm 0.014$ & 1.24 & 1.24 & $2.71 \%$ & $1.08 \pm 0.017$ & 1.06 & 1.058 & $2.29 \%$ \\
\hline 0.5 & $1.21 \pm 0.013$ & 1.22 & 1.22 & $0.74 \%$ & $1.10 \pm 0.018$ & 1.06 & 1.063 & $3.66 \%$ \\
\hline 0.6 & $1.20 \pm 0.012$ & 1.20 & 1.2 & $0.72 \%$ & $1.08 \pm 0.019$ & 1.06 & 1.064 & $1.47 \%$ \\
\hline 0.8 & $1.20 \pm 0.012$ & 1.17 & 1.17 & $2.15 \%$ & $1.11 \pm 0.017$ & 1.06 & 1.061 & $3.97 \%$ \\
\hline 1 & $1.17 \pm 0.014$ & 1.16 & 1.16 & $1.03 \%$ & $1.09 \pm 0.015$ & 1.06 & 1.062 & $2.39 \%$ \\
\hline 1.5 & $1.13 \pm 0.017$ & 1.14 & 1.14 & $0.89 \%$ & $1.12 \pm 0.014$ & 1.06 & 1.064 & $5.38 \%$ \\
\hline 3 & $1.11 \pm 0.018$ & 1.11 & 1.11 & $0.77 \%$ & $1.05 \pm 0.013$ & 1.07 & 1.070 & $1.78 \%$ \\
\hline 6 & $1.08 \pm 0.02$ & 1.10 & 1.11 & $2.75 \%$ & $1.06 \pm 0.008$ & 1.07 & 1.103 & $3.77 \%$ \\
\hline 10 & $1.09 \pm 0.01$ & 1.10 & 1.1 & $1.13 \%$ & $1.04 \pm 0.010$ & 1.08 & 1.073 & $3.48 \%$ \\
\hline
\end{tabular}

